Buğrul, Hasan (2019). "Van - Hakkâri İlleri Kültür ve Sanatında Kuşlar”. Uludağ Üniversitesi Fen-Edebiyat Fakültesi Sosyal Bilimler Dergisi, C. 20, S. 36, s. 477512.

DOI: $10.21550 /$ sosbilder.466180

\title{
VAN - HAKKÂRİ İLLERİ KÜLTÜR VE SANATINDA KUŞLAR \\ Hasan BUĞRUL*
}

Gönderim Tarihi: Ekim 2018

Kabul Tarihi: Kas1m 2018

ÖZET

Van ve Hakkâri illeri sanat ve kültürü irdelendiğinde kuşların bunlarda büyük bir yere sahip olduğunu söyleyebiliriz. Tarihi eser olarak Akdamar Kilisesi ve Yedikilise Manastırı bu yönüyle dikkat çekerler. Figürlerine yer verilen kuşlar arasında bölgede rastlanılan türler yanında "tavus" kuşu gibi bölgede rastlanılmayan kuş türlerini de görmekteyiz. Dokuma ve örgü eserler üzerinde de slkça kuş figürlerine rastlanmaktadır. Kültürel etkileşimde insanların farklı yönleriyle kuşlara benzetilmesine sıkça yer verilmektedir. Bu anlamda; kartal, turna, bülbül, hüthüt, kaya güvercini, leylek, kınalı keklik, suna, karga ve serçe gibi kuşlar öne çıkmaktadır. Yapılan araştırmalarda, Van-Hakkâri yöresi kültür ve sanatında kuşların etkisi ile bağlantılı detaylı bir çalışmaya rastlanılmamıştır. Bu çalışma ile bu alandaki boşluğun doldurulması ve yörenin kültür, sanat ve turizmine katkıda bulunulması hedeflenmiştir.

Anahtar Kelimeler: Van, Hakkâri, kuşlar, kültür, sanat

* (D) Dr. Öğr. Üyesi, Van Yüzüncü Yıl Üniversitesi Van Meslek Yüksekokulu Seyahat-Turizm ve Eğlence Hizmetleri Bölümü, hbugrul@yyu.edu.tr

Uludağ Üniversitesi Fen-Edebiyat Fakültesi Sosyal Bilimler Dergisi Uludağ University Faculty of Arts and Sciences Journal of Social Sciences Cilt: 20 Sayl: 36 / Volume: 20 Issue: 36 


\section{Birds in Culture and Art of Van-Hakkâri Provinces}

\section{ABSTRACT}

Considering the art and culture of Van and Hakkâri, we can say that birds also appear to have a great place in them. As historical monuments, Akdamar Church and Yedikilise Monastery attract attention from this aspect. Besides giving a place to the figures of the birds found in the region, we see bird species such as "peacock" which is not encountered in the region. Stylized bird figures are also frequently found in weaving and knitting works. It is common for people to be compared to birds in different aspects. In this sense; the birds such as eagles, crane, nightingale, hoopoe, rock dove, stork, rock partridge, shelduck, crow and sparrow come to the fore. In the researches conducted, a detailed study related to the effect of birds in Van-Hakkâri region culture and art was not found. In this study it is aimed to fill the gap in this area and contribute to culture, art and tourism of the region.

Key words: Van, Hakkâri, birds, culture, art

\section{Giriş}

İnsan içinde yaşadığı dünyanın yanı sıra farklı bir evren ve çevresinde gördüğü varlıklar dışında da birtakım yaratıkların olabileceğini zihninde hep canlı tutmuştur. Bunun neticesinde de kültür ve sanatımızda çevremizde gördüğümüz gerçek varlıklar dişında mitolojik bir takım yaratıkların da yer aldığı görülür. Hayal edilen yaratıklar arasında kuşlar da önemli bir yer tutmaktadır. Mitolojik olarak adlandırılan bu kuşların her türünün farklı özellikleri bulunmaktadır. Bunlar arasında şans, uğur, talih getiren kuşların olduğu ve bir gün bunlar vasıtasıyla hayallerini gerçekleştirebileceklerini düşünmüşler. Bunun yanı sıra çevrede görülen kuşların her birinin özelliğine göre de bir anlam biçilmiş ve bu düşünceler kültür ve sanatta yer edinerek nesilden nesile günümüze kadar ulaşmıştır.

Van ve Hakkâri illerimiz zengin bir kuş potansiyeline sahiptir ve bu illerimizde farklı dönemlere ait birçok sanat eseri üzerinde kuşlarla bağlantılı sanata rastlandığı gibi bu illerde yaşayan insanların 
kültüründe de önemli derecede yer edindikleri görülür. Bu kültür, geçmişten günümüze gelen kuşlarla bağlantılı bir birikimi kapsar.

Elde edilen bilgiye göre, bu bölgede kuş türleri açısından zengin olmasını sağlayan faktörlerinden biri "önemli kuş göç yolları" üzerinde yer alması ve bir diğeri de çok sayıda sulak alanlara sahip olmasıdır. Bu konuda Durmuş vd. (2013: 194) şu bilgilere yer verirler: Havzada 1998 yılından beri yapılan ornitolojik veriler sonucunda, havzada yaşayan kuş türü sayısının 142 den 213 'e çıktığı tespit edilmiştir. Aynı zamanda ornitolojik araştırmalar yaygınlaştıkça sayının 300'lere kadar ulaşabileceği düşünülmektedir (Adızel 1998; Adızel vd. 2011).

\section{2. İslam Öncesi Türk Kültüründe Kuşlar}

İslam öncesindeki bozkır sanatında (hayvan üslubunun) kuşların da önemli bir yere sahip olduğu görülür. Çoruhlu (1988: 152-153), kuşların insanlar üzerindeki farklı etkilerini şu şekilde aktarır: Bilindiği gibi kuğu ve kaz gibi bazı kuşlar Orta Asya'da ve Çin'de çok eski çağlardan beri kutsal sayılıyordu. Örneğin bıldırcın yiğitliğin; sülün güzellik ve iyi şansın; saksağan iyi haberin; turna ölümsüzlüğün ve uzun hayatın; altın ya da kırmızı karga güneşin; karakarga şeytanın ve kötülüğün; ördek, mutluluk ve refahın; tavus güzellik, itibar ve şerefin; güvercin uzun hayatın; kaz erkekliğin, evliliğin ve başarının simgesi olmuştur. Kaz ve kuğu gibi kuşlar Türklerde beylik timsali olmuştur.

\subsection{Mitolojik Kuşlar}

Türk kültürü ve sanatında her birinin farklı özelliğe sahip olduğu varsayılan birçok mitolojik kuş vardır ve "anka" ile "hüma" en yaygın söz edilenler arasında yer alırlar. İkisinin benzer unsurların sembolü olarak değerlendirilmesi eleştiriye sebebiyet vermektedir. Ögel (2003: 108-109), bu iki kuşla ile ilgili şu hususlara yer verir: Ön Asya mitolojisinde başlıca iki önemli efsanevi kuş vardır. Bunlardan birincisi Arapların "Anka dedikleri kuştur ki, biz Türkler bu kuşun Farsça ve Arapça adlarını birleştirerek Zümrü-dü Anka deriz. Aynı kuşa İran mitolojisi ise Simurg veya Sireng adını verirdi... Yine daha sonraki İran 
mitolojisinde bu kuşun Kaf veya Elburz dağlarında oturduğu söyleniyordu. $\mathrm{Bu}$ kuşun tüyünü ele geçirenlerin en büyük sirra ve ölümsüzlüğe erecekleri iddia ediliyor ve efsanelerde böyle yazıliyordu. Humay veya Türkçe Hüma kuşu ise daha başkadır. Peygamberin hadislerinde ve İslami edebiyatta da geçen bu kuş, bir Cennet kuşudur... Hüma kuşu için erişilmeyecek bir yer yoktur. Onun için İslamiyet'te Allah'ın mekânsız olduğunu göstermek için, Hüma kuşu örnek olarak gösterilmişti... Hüma, erişilmeyecek yüksekliklerin bir sembolü idi.

\section{2 İslam Öncesi Türk Kültüründe Önemli Bir Yere Sahip Kuşlar \\ 2.2.1 Kartal}

Kuşlarla ilgili Türk kültür ve mitolojisi irdelendiğinde "anka" ve "hüma" gibi efsane kuşlarının yanı sıra "kartal, kuğu, turna, karga ve kaz" gibi kuşların ön plana çıktığı görülür. Ögel (2003: 47), kartal ile ilgili olarak şunları ifade eder: Kartal, Yakut şamanlarına göre en yüksek ruhları taşıyan hayvanlardır. Bazı kabileler bu hayvanlardan veya değişik cinslerinden türediklerine inanmaktadırlar. Kartal aynı zamanda tanrı ile şaman arasında elçi vazifesini görmektedir.

\subsection{2 Çift Başlı Kartal}

"Çift başlı kartal" İslam öncesi Türk kültür ve sanatında olduğu gibi Anadolu Selçuklu döneminde de önemli bir yere sahip olduğu görülür. Daşdağ (2017: 312), kartalın çok yükseklerde uçması, çok uzaktaki unsurları seçebilmesi, hızı, gücü vb. özelliklerini şu hususlarla özdeştirir: Kartalın Türklerde koruyucu ruh kabul edildiği için özellikle silahlarda ve mimari yapılarda kullanıldığı düşünülmektedir. Genellikle kartal göklerin hâkimi olup, güç simgesidir. Koruyan ve egemenlik kuran iki ruhun ya da iki iktidarın güç birliği durumlarında iki kez artırılmış gücünü simgelemektedir. Türklerde kartalın ve doğanın önemli bir yeri vardır. "Yakutlara göre, göğün en üst katında ve göğün yere açılan kapısında, yeri gögü bağlayan Dünya Ağacı'nın tepesinde 
çift başlı bir kartal otururdu. Göklerin korunması bu kartalın vazifesiydi." (13) Yine Yakut Türklerinde and, kartalın adıyla içilir. Evlerinin çevresinde kartal gören Yakutlar, ona et ziyafeti çekerler. Yanlışlıkla bir kartalı öldürürlerse cenazesini törenle şamana kaldırtırlar. Asya'da bebeksiz kadınlar, kendilerine yavru bağışlaması için kartala yalvarırlardı.

\subsubsection{Karga ve Kaz}

Karganın farklı toplumların kültüründe genellikle olumsuz yönüyle ön plana çıkarılırken İslam öncesi Türk kültüründe olumlu yönde bakıldığı, Türkler tarafından ata olarak kabul edildiği görülür. Ata olarak kabul edilen diğer kuşlar arasında "turna ve kaz" gibi kuşların da yer aldığını Sever (1999: 85), şu şekilde belirtir: Yabani kaz, yüksek mertebeli kimselerin timsali idi. Kaz ve Korday (kuğu) Türklerde beylik ve kut timsali idi... Kaz da Türk mitolojisinde önemli bir yer tutar. Altay şamanların davulları üzerinde kaz ile kartal resimleri bulunurdu. Kaz, Türk mitolojisinde çok akıllı ve bilgiç bir kuştur. O, Şamanizm'in kanun ve adetlerini iyi bilir. Kam'a hangi ilahı ziyaret etmesi, hangi yoldan gitmesi ve ilahın huzuruna nasıl çıkılması gerektiğini öğütler.

\subsubsection{Turna}

Temizkan (2014: 165-166), "turna" kuşunun "ata" olarak kabul edilmesinin yanında Yamaeva'dan vd. (1994: 353) bu kuş ile ilgili yansımaları şu şekilde aktarır: Altay Türkleri arasında kutsal kabul edilen kuşlardan biri, turnadır. Eşli ve eşine sadık kuşlardan biri olan turnanın öldürülmesi kesinlikle yasaktır. Özellikle halk hikâyelerinde turna, haber getiren, kendisinden haber sorulan, dertleşilen bir kuştur. Sıladan veya sevgiliden haber getirir. Turna da tanrıya ulaşmak için bir elçi bir aracı idi ve muhtemelen şamanın ruhunu da temsil ederdi. 


\subsubsection{Kuğu}

Türk kültüründe önemli bir yere sahip diğer kuşlardan biri de kuğudur. Çoruhlu (1988: 35-36), bu kuş türü ile ilgili şu noktalara yer verir: Kuğu'nun Türk mitolojisinde ve özellikle Hint mitolojisinde önemli bir yeri vardır. Bazen tanrılığın ve kutsal kadınlığın simgesi olarak düşünüle kuğu bazı Yakut kabilelerinin totemi ve türediklerine inandıkları bir hayvan idi. Kuğu şekline girme olayı Türk ve Hint mitolojilerinde görülen önemli bir inanç motifidir. O İslam döneminde Türklerde kalp temizliğinin simgesi idi. Türklerde bazı ruhların kuğu şekline girdiği inancı yaygın olarak görülür.

\subsubsection{Atmaca}

Daşdağ (2017: 310), atmaca kuşu ile ilgili olarak Baş'tan şu hususları aktarır: Hükümdarın kuvvet ve kudretini öven ifadeler, kutsal savaş kahramanı, dünyanın güneşi, insanlığın savunucusu gibi sembolik anlamları taşıyan atmaca ile görselleştirilmiştir (Baş 2006).

\section{Van - Hakkâri İlleri Sanatında Kuşlar}

Van'daki tarihi eserlerden Akdamar kilisesi ve Yedikilise Manastırı üzerinde kuş figürlerinin güzel örneklerine rastlanır. Hakkâri'de ise farklı hayvan figürleriyle beraber kuş figürlerini daha çok kilim ve çorap gibi el sanatlarında yaygın olarak görebiliriz.

\subsection{Van Yedikilise Manastırı Üzerinde Bulunan Kuş Figürleri}

Akdamar Kilisesi ve Yedikilise Manastırı'nda görülen bezemeler arasında kuş figürleri önemli bir yere sahiptir. Yedikilise Manastırı üzerinde genellikle ötücü türden kuş figürlerinin olduğu görülür. Bunlar arasında sığırcık, güvercin, leylek (akleylek), kuğu, karga, bülbül ve kaz vardır. Karaca (2017: 972), Yedikilise Manastırı'ndaki kuş figürleri konusunda şu hususlara yer verir: İncelediğimiz yapıda 13 ayrı haç işlemeli taş üzerinde çiftler halinde 26 adet kuş figürü bulunmaktadır. Kuşlar haçkarların alt köşelerinde olup her çift aynı tür olarak işlenmiştir. Toplamda 10 ayrı kuş türü olduğu belirlenmiştir. Jamatunun 
batı cephesindeki taçkapının güneyindeki 22 adet haç işlemeli taştan (haçkar) 9 tanesinde kuş figürleri yer almaktadır. Haçların alt köşelerinde karşılıklı duran, simetrik olarak çiftler halinde birbirine orantılı olarak yapılmış 18 adet kuş bulunmaktadır. Taçkapının kuzeyindeki dizi şeklinde devam eden 21 adet haç işlemeli taştan 3 tanesinde karş1lıklı çiftler halinde toplam 6 adet kuş figürü vardır.

\subsection{Van Akdamar Kilisesi Üzerinde Bulunan Kuş Figürleri}

Akdamar kilisesi diş cephesi üzerinde yer alan "tavus kuşu" dışındaki kuğu, suna, küçük yırtıcılar, kartal, kerkenez, beç tavuğu, horoz, keklik, bıldırcın, toy kuşu, martı, güvercin, kumru ve karganın Van Gölü Havzasında yaşayan kuş türlerinin olduğu görülür. Kabartma tekniği ile yapılan mimari plastik süslemelerdeki kuşların bir kısmının süsleme unsuru olmasının yanında ikonografik açıdan anlamlar taşırlar. Bunlardan bazılarını Hristiyan kültürü açısından irdeleyecek olursak:

\subsubsection{Kuğu / Kaz}

Tomislav (2016: 447), Yunan mitolojisinde "kaz/kuğu"1 ile ilgili ortaya konulan görüşlerden birisini şu şekilde açıklar: (MS 4. yüzyıl sonları - 3. yüzyıl başları) Apollo bir koşu atına değil, muhtemelen savaş arabasını çeken, kanatlı bir kaz/kuğuya sahipti veya onu üzerinde taşıyan (D. 38.206).

\subsubsection{Kartal}

$\mathrm{Kartal}^{2}$, hızı ile yıldırım ve şimşekle, çok yükseklerde uçuşu ile güneşle ve cennetle ilişkilendirilir. Bunun yanında farklı kültür ve inançlarda güç, diriliş, yeniden doğuşun sembolü olarak görülür. Akdamar Kilisesi üzerinde yer alan bazı kuşlar "üzüm" ile tasvir edilmiştir. Collins (1913: 32), bu tarz tasvirlerin (kuşların üzümü gagalaması) Hristiyanlık inancında ebedi yaşama, ruhun ebedi yaşama

\footnotetext{
${ }^{1}$ Bk. Ek 1.

${ }^{2}$ Bk. Ek 2.
}

Uludağ Üniversitesi Fen-Edebiyat Fakültesi Sosyal Bilimler Dergisi Uludağ University Faculty of Arts and Sciences Journal of Social Sciences Cilt: 20 Sayı: 36 / Volume: 20 Issue: 36 
ulaşmasına işaret olabileceği şeklindeki değerlendirilmeyi şu şekilde yapar: Kartal ile ilgili aktardıklarına bakacak olursak; Kartal yaşlandığında ve neredeyse kör olduğunda, ta ki güneşin sicağında kanatlarını yakana kadar havaya uçar. Sonra doğrudan üç kez düz suya dalar ve bir kez daha ondan genç bir kartal ortaya çıkar. Balıkların aşağıda yüzdügünü gördüğü zaman bir dalış yapar ve balığı kendisi için yakalar. Buradaki kartal Tanrı'nın göz kamaştıcı nuruna bakabilen İsa'y1 temsil ediyor.

\subsubsection{Tavus Kuşu}

Tavus kuşu ${ }^{3}$, ilkbahar, doğum, yeni nesil, uzun ömür, sevgi, iyi ilham kaynağı, başarılı ilişkilerin ve meslekte başarı kazanmanın simgesi gibi olumlu kavramların simgesi olmasının yanında göz alıcı güzel tüylerinin görüntüsü kibir, gurur ve gösterişin bir işareti olarak görülür. Kuyruk tüylerindeki halka desenler yıldızların, evrenin, güneşin, ayın ve "gök kubbenin" aynı zamanda her şeyi gören Tanrı'nın sembolü olarak değerlendirilir. Collins (1913: 33), tavus kuşunun ölümsüzlüğün simgesi olduğu görüşünü şu şekilde ortaya koyar: Çünkü onları baharda daha ihtişamlı bir şekilde geri kazanmak her yıl kuyruğundaki tüyleri döker. Şimdiye kadar bilindiği kadarıyla, tavus kuşu mimari tasarımda gururun simgesi değildir. Bir görüşe göre, tavus kuşu uyandığında, korku içinde haykırır çünkü rüyasında güzelliğini kaybettiğini görür.

\subsubsection{Horoz}

Horoz $^{4}$; cesaretin sembolü olarak görülür. Horoz dövüşüne bakıldığında tarih öncesine kadar dayandığı; Hindistan, Çin, İran ve diğer Doğu ülkelerinden sonra Yunanistan'da, sonrasında da diğer Avrupa ülkelerine yayıldığı bilgisine rastlanmaktadır. Horoz dövüşünün birçok farklı sanat unsurunun üzerinde yer aldığı görülür. Collins (1913:

\footnotetext{
${ }^{3}$ Bk. Ek 3.

${ }^{4}$ Bk. Ek 4.
}

Uludağ Üniversitesi Fen-Edebiyat Fakültesi Sosyal Bilimler Dergisi Uludağ University Faculty of Arts and Sciences Journal of Social Sciences Cilt: 20 Sayl: 36 / Volume: 20 Issue: 36 
28), "horoz dövüşünün" daha çok zorluklara karşı direnişi simgelediğini şu şekilde açıklar: Beyaz horoz kutsal hayata sahip kişiyi simgeliyor. İlk yazarlar, horozun ihtiyatlık ve cömertlik anlamlarına sahip olduğunu ifade ederler. Bu ikincisi önemlidir çünkü yiyecek yolunda bulduğu her şeyi yemez, paylaşmak için tavuklara çağrıda bulunur.

\subsubsection{Güvercin}

Güvercin $^{5}$ figürü, saflı̆̆ın, masumiyetin yanı sıra haberleşmenin sembolü olarak değerlendirilir. Bir hikâyeye göre, Nuh Peygamber suların yer yüzeyinden çekilip çekilmediğini öğrenmek için gemisinden bir güvercini gönderir ve güvercinin ağzından bir zeytin yaprağı ile dönüşüyle suyun çekildiği anlaşılır. Collins (1913: 30) güvercinin Hristiyanlık inancındaki yerini şu şekilde aktarır: Güvercin gagasında bir zeytin dalı taşıdığında, genellikle Nuh ve gemisi ile bağlantılıdır ve önemi aşağıdaki gibidir. Tıpkı güvercin gibi nasıl ki ayak tabanlarını gemi dışında dinlendirebilecek güvenli hiçbir yer bulamıyorsa, Hıristiyan da ruhunu Kilise'nin dişında hiçbir yerde güvenli ve huzurlu bulamaz. Bazen güvercin sadece zararsız bir Hıristiyanın hayatını temsil eder. Bunun için, Rabbimiz, güvercinler gibi zararsız olmamızı söyler. Fakat güvercin genellikle Kutsal Ruh'u simgeliyor.

\subsubsection{Keklik}

Keklik $^{6}$, iyi anlamda, gerçeğin, dürüstlüğün yanında hilekârlık ve aldatma gibi kötü anlam taşıyan kavramların da sembolü olarak görülür. Akdamar kilisesi üzerinde kabartma olarak yer verilen keklik figürü üzüm gagalarken betimlenmiştir. Bu anlamda, kekliğin üzümle betimlenmesi, muhtemelen kartal gibi ebedi yaşamı, ruhun ebedi yaşama ulaşmasını sembolize eder.

\footnotetext{
${ }^{5}$ Bk. Ek 5.

${ }^{6} \mathrm{Bk} . \mathrm{Ek} 6$.
}

Uludağ Üniversitesi Fen-Edebiyat Fakültesi Sosyal Bilimler Dergisi Uludağ University Faculty of Arts and Sciences Journal of Social Sciences Cilt: 20 Sayı: 36 / Volume: 20 Issue: 36 


\subsection{Hakkâri Dokuma Eserleri Üzerinde Görülen Kuş Figürleri}

Kuş figürünün üzerinde yer aldığı diğer unsurlar arasında dokuma ve örgü işlerini de saymak mümkündür. Dokumada ve örgüde önemli bir yere sahip olan Hakkâri ve Van illerimize ait kilimler ve yün çoraplar üzerindeki bezemede kuş figürü de önemli bir yere sahiptir. $\mathrm{Bu}$ unsurlar üzerinde yer alan kuşlar figürleri daha çok "muhabbet, sevgi, aşk" ile bağlantılıdırlar. Hakkâri kilimlerini emsalleriyle kıyasladığınızda hem tarihi geçmişi bakımından hem de malzeme ve bezemesiyle en ön plana çıktıkları görülür. Bu sanat eserleri üzerindeki bezeme zenginliği içerisinde farklı hayvanlara ait figürler arasında "kuş figürleri” de önemli bir yere sahiptir. Kuş figürlerine bakıldığında, dokumacının hayal ettiği ve kafasında oluşturduğu bazı farklı kuş türlerinin yanı sıra, "hüthüt" kuşu ${ }^{7}$ gibi inançla bağlantılı kuş figürlerine de yer verildiği görülür. "Muhabbet kuşu" ${ }^{8}$ denilen stilize kuş figürü de kilimlerde sıkça rastlanan motifler arasında yer alır.

\section{Van - Hakkâri İlleri Kültüründe Kuşlar}

Kuşların toplumların sanat eserlerinde ve kültüründe yer edinmesi genellikle belirli inanç, düşünce ve farklı algılamalara bağlı olarak ortaya çıktığı görülür. Konya Mevlevi dergâhında bulunan ve nisantası olarak adlandırılan bir kap üzerindeki kabartma "horoz, kaz, karga ve tavus" kuşu figürleriyle ilgili yapılan bir açıklama buna iyi bir örnektir. Musul'dan getirilen ve Miladi 1333'e tarihlendirilen bu bakır tas (Nisan'da yağmur suyunun toplanıp dua edildikten sonra şifa ve bereket getirmesi niyetiyle bu suyun dağıtımında kullanılan kap) üzerinde yer alan kabartma kuş figürleriyle ilgili değerlendirme Bakara Suresi'nin 260. ayetinin meali ile irtibatlandırılmaktadır:

\footnotetext{
${ }^{7}$ Bk. Ek 7.

${ }^{8}$ Bk. Ek 8 .
}

Uludağ Üniversitesi Fen-Edebiyat Fakültesi Sosyal Bilimler Dergisi Uludağ University Faculty of Arts and Sciences Journal of Social Sciences Cilt: 20 Sayı: 36 / Volume: 20 Issue: 36 
Hani İbrahim: "Ey Rabbim! Ölüye nasıl hayat verdiğini bana göster!" demişti. (Allah da:) "Ne o, yoksa inanmadın mı?" diye sormuştu. O da: "Hayır (inandım), ama (görmeme izin ver) ki kalbim tamamen yatısssın" dedi. Bunun üzerine Allah buyurdu ki: "Öyleyse dört tane kuş yakala, onları yanına al, sonra (kesip parçala), her dağın başına onlardan bir parça koy. Sonra da onları kendine çağır; koşarak (uçarak) sana gelirler. Muhakkak ki Allah mutlak galiptir, hüküm ve hikmet sahibidir.

Oral (1954: 4), Bakara Suresi'nin 260.nc1 ayetinin ilham alınarak bu dört kuş ile ilgili şu değerlendirmelere yer verir: Bu dört kuş mesnevi-i şerifte izah edilirken (kaz, tavus, karga ve horoz)dur. Bunlar insandaki dört huyun misalidir. Kaz hırsa, horoz şehvete, tavus dünya mertebelerine, mansiplarına yani servet, süs ve ziynetlerine karga da tul-i amele işaret teşbih edilmiştir.

Van ve Hakkâri yöresinde kuşlarla ilgili kültürün zenginliği dikkat çeker. İnsanların bazı davranış biçimlerinin farklı kuşlarla özdeştirildiği görülür. Kutsal olarak kabul edilen "güvercin" ve "hüthüt" gibi kuşlara asla zarar verilmez. Diğer kuşların avlanması veya zarar verilmeye çalışılması da yine kuşların dilinden engel olunmaya çalışılması yörede hayvanlara verilen değerin bir göstergesi olarak görmek mümkündür.

\subsection{Hüthüt Kuşu}

Hüthüt kuşu'; anka, hüma, kaknus ve semender gibi efsane kuşlar arasında yer almakla birlikte Kur'an'da ismi ve bununla bağlantılı bilgilere yer verilmesiyle İslam kültüründe önemli bir yere sahiptir ve kutsal sayılmaktadır. Van ve Hakkâri çevresinde de kutsal sayılmaktadır ve asla zarar verilmez. Eskigün (2006: 37-38), hüthüt kuşu ile ilgili olarak şu bilgileri aktarır: Süleyman peygambere hizmet eden hüthüt çok uzaklardaki suyu havadan görebilme ve keşfedebilme

\footnotetext{
${ }^{9}$ Bk. Ek 9.
}

Uludağ Üniversitesi Fen-Edebiyat Fakültesi Sosyal Bilimler Dergisi Uludağ University Faculty of Arts and Sciences Journal of Social Sciences Cilt: 20 Sayl: 36 / Volume: 20 Issue: 36 
maharetinden ötürü, Süleyman Peygambere ve ordusuna kılavuzluk eden olağanüstü bir kuştur

Belli başlı özellikleri arasında toprağın altındaki suyu görmesi, eşine olan bağlılığı, eşi ölünce yeni bir eş aramaması, anne babasına karşı hürmetkârlığı sayılabilir. Hüthüt yaşlandıklarında anne ve babasının yiyeceklerini temin eder. Annesi öldüğünde uygun bir yer buluncaya kadar onu başında taşıdığı için mükâfat olarak güzel bir tepelikle donatılmıştır. (Câhız, III, 510-514; Demîrî, 11, 436-440)... Hüthüt Hz. Süleyman'ın Seba Melike'sine elçi olarak gönderdiği kuş olması bakımından önemlidir. Ancak hüthütün asıl önemi bütün kuşlara öncülük ederek onları Kafdağı'nın ardındaki kuşların şahına götürmesidir. $\mathrm{Bu}$ yönüyle hüthüt (ibibik) doğruluk, isabet ve menzile ermenin göstergesidir. $\mathrm{O}$, harekete geçtiğinde diğer bütün kuşların ona uymas1 gerekir.

\subsection{Kartal / Çift Başlı Kartal}

Kartal $^{10}$ ve çift başlı kartal olağanüstü kuşlar arasında yer alırlar. Alp (2009: 54), onlarla özdeştirilen temalara şu şekilde yer verir: Sanat eserleri üzerinde Anadolu Selçuklularında çift başlı kartal, aslan ve ejder motifleri birer hükümdarlık, kudret ve kuvvetin ve aynı zamanda da ışığıı sembolü olmuştur. Bu figürler kullanıldıkları yere göre değişik anlamlar da almaktadırlar. Anadolu Selçuklularında boğa, ayı, kartal ve aslan güneşi sembolize eder. Çift başlı kartalın hem geçmişe hem geleceğe bakmayı, politik nedenlerle birleşmeyi de sembolize ettiği düşünülebilir.

Özel (2018: 554), kartal ile ilgili değerlendirmeyi Öğel'den (1972: 217) şu şekilde aktarır: Kartalın çift başlı yapılmasının sebebi, Türk sanatındaki simetri tutkusudur, koruyan ve egemenlik kuran iki ruhun, iki iktidarın güç birliği durumlarında iki kez arttırılmış gücün, çift başlı kartalla simgelendiğini belirtmektedir.

${ }^{10}$ Bk. Ek 10.

Uludağ Üniversitesi Fen-Edebiyat Fakültesi Sosyal Bilimler Dergisi Uludağ University Faculty of Arts and Sciences Journal of Social Sciences Cilt: 20 Sayl: 36 / Volume: 20 Issue: 36 
Yörede birisinin bir başkasına ani saldırısı, çok hızlı davranması olayı "kartal gibi saldırdı" deyimi sıklıkla kullanılır. Kuşların diline aşina olarak bilinen Vanlı (Bahçesaray ilçesinden) Feqiye Teyran'ın (Muhammed) birçok özelliğinin kartalla özdeştirildiği görülür.

\subsection{Kınalı Keklik}

Fiziki olarak güzel olan bir kadın kınalı kekliğe ${ }^{11}$ benzetilir. Sinecen (2017: 121), keklik ve benzer özellikteki kuşlar hususunda şu bilgilere yer verir: Belki daha yaygın olarak alıcı kuşlar sevgiliyi simgelemektedir. Bir keklik, kumru, güvercin, serçe acizliğinde olan âşık veya âşığın gönül kuşu karşısında sevgili, bu gönül kuşlarını avlayan şahbaza benzetilir.

\subsection{Suna}

"Suna" ${ }^{12}$ kuşunun su içinde çok zaman geçirir ve çok temiz bir görünüme sahiptir. Suna kuşunun bu özelliği temiz ve bakımlı kadının simgesi olarak görülür. Özellikle su ile temizlik işlerine çok yer veren bir kadın için; sanki bu kadın su üzerindeki "suna kuşudur", denir. (Kaynak kişi: Anber Buğrul).

\subsection{Karga}

"Karga"13 kuşunun farklı türleri vardır ve bunlar arasında karakarganın genel olarak olumsuz bir şekilde değerlendirildiği görülür. Sinecen (2017: 125), bu konuda şu bilgilere yer verir: Karga, kara olması ve leşle beslenmesi yönlerinden olumsuz sayılan kuşlardan biridir. Dolayısıyla ilahi güzelliklerin tecelli ettiği hakikatleri algılamayan kalabalıkları sembolize ediyor olması boşuna değildir.

Karga ile ilgili olumuz düşüncelerin yanı sıra farklı şekillerde değerlendirildiği de görülür. Nitekim İslam öncesi Türklerde "ata"

\footnotetext{
${ }^{11}$ Bk. Ek 11.

${ }^{12}$ Bk. Ek 12.

${ }^{13}$ Bk. Ek 13.
}

Uludağ Üniversitesi Fen-Edebiyat Fakültesi Sosyal Bilimler Dergisi Uludağ University Faculty of Arts and Sciences Journal of Social Sciences Cilt: 20 Sayl: 36 / Volume: 20 Issue: 36 
olarak görülen kuşlar arasında yer alır. Van ve Hakkâri yöresinde karganın "iyi veya kötü" haberi de getirebileceğine inanılır. Böylece uğurlu veya uğursuz olabiliyor. Yörede karga ile ilgili söylenen sözleri Hakkâri'nin Yüksekova İlçesi'nde Selim Bulut şu şekilde aktarır:

Tablo 1: Halk arasında karga ile ilgili söylenen sözler

\begin{tabular}{|l|l|}
\hline $\mathbf{1}$ & \multicolumn{1}{c|}{ Türkçe anlamı } \\
\hline Hekê xêrbe bi qire & Eğer hayra ise öt \\
Hekê xêr nebe bi fire & Hayra değilse uç git \\
\hline $\mathbf{2 -}$ & \multicolumn{1}{|c|}{ Türkçe anlamı } \\
\hline Heke xêre be dane here & Eğer hayra ise birak git \\
Heke şêr be hıldê here & Eğer şer ise al git \\
\hline
\end{tabular}

\subsection{Güvercin}

Güvercin $^{14}$, İslam kültürünün yanı sıra Musevi ve Hristiyanlarca da değer verilen bir kuş türüdür. Aile büyükleri çocuklarına Peygamberimizin hicreti sırasında O'nun kurtuluşunda güvercinin oynadığı rolden sıklıkla bahsederler. Bunun için de bu kuş türüne büyük sevgi beslenir, kutsal kabul edilir ve avlanmaz. Yörede "kaya güvercini” yaygın olarak görülür. Güvercinin birçok inançta kutsal sayılması neticesinde sanat ve kültürel yansıması da yaygındır. Parla (2015: 6), güvercin ile ilgili olarak Hançerlioğlu'ndan şu bilgiler aktarılmaktadır: Hz. Muhammed'in saklandığı mağarada örümcek ağlarının üstüne yuva yaparak onu gizlediği ve koruduğu için İslam dünyasında ayrıca kutsanan bir varlıktır. Eski Ahit'e göre, tufanın bitip bitmediğini anlamak için Nuh peygamberin uçurduğu güvercin, ağzında bir zeytin dalıyla geri dönünce insanlarla tüm yaratıklar karaya çıkabilmiş ve soylarını devam ettirebilmişlerdir. Öte yandan, güvercinin tasavvufta ermiş kişilerin ruhu olduğuna, ermişler uyurken ruhlarının bir güvercin olarak bedenlerinden çıkarak bütün kutsal yerleri dolaştıklarına, Hızır'ın güvercin kılığında insanların karşısına çıktığına

${ }^{14}$ Bk. Ek 14.

Uludağ Üniversitesi Fen-Edebiyat Fakültesi Sosyal Bilimler Dergisi Uludağ University Faculty of Arts and Sciences Journal of Social Sciences Cilt: 20 Sayl: 36 / Volume: 20 Issue: 36 
inanılmış, yapıların duvar ve çatılarına güvercinler için özel barınaklar yapılmıştır.

\subsection{Serçe}

Serçe ${ }^{15}$, kuşlar arasında en küçük türlerden biridir ve çok yaygın olduğu görülür. Bu küçük kuşun avlanması hoş karşılanmaz ve bunun tepkisi yine serçe kuşu konuşturularak gösterilir. Hakkâri'nin Çavuşlu Köyü'nden Anber Buğrul (88), serçe kuşunu avlayan kişilere karş1 söylenen sözleri kuşların dilinden şu şekilde aktarır:

Tablo 2. Halk arasında güvercinin avlanması ile ilgili söylenen sözler:

\begin{tabular}{|l|l|}
\hline \multicolumn{1}{|c|}{ Halk arasında söylenen sözler } & \multicolumn{1}{c|}{ Anlamı } \\
\hline İnsano! Çaw tarîyo! & Ey gözü dönmüş insan! \\
Kuştinamın yêk parîyo. & Öldürülmem tek lokma içindir. \\
Te çi pê xariyo? & Bununla eline ne geçiyor? \\
\hline
\end{tabular}

\subsection{Baykuş}

Baykuş $^{16}$, bilgeliğin sembolü olarak görülmesinin yanında şans veya tam zit kavram olan şansızlık, ölüm ile ilişkilendirilir. Bununla ilgili ilginç bir inanışı Hakkâri'nin Çavuşlu köyünden İsmail Güler (75) şu şekilde aktarır: Kendisini öldürmek üzere ateş açılıp da kurtulan baykuş havalanıp başka bir yere konar. Ancak bu durum onu çok öfkelendirir ve üzer. "Benim ne kabahatim vardı, sana ne zararım oldu da beni öldürmeye kalkıştın?", der ve kahrından orada can verir. Bu kuş ile ilgili olarak aktarılan hususlar arasında şunlara da yer verilir: Dünya geçici olması, kalıcı olmaması ile bir viraneliğe benzetilir. Bilindiği gibi baykuşlar da virane, harabe yerlere konup öterler. Baykuş, özellikle ötüşü ile kültürümüzde uğursuzluğun göstergelerinden olmuştur.

\footnotetext{
${ }^{15} \mathrm{Bk}$. Ek 15.

${ }^{16} \mathrm{Bk}$. Ek 16.
}

Uludağ Üniversitesi Fen-Edebiyat Fakültesi Sosyal Bilimler Dergisi Uludağ University Faculty of Arts and Sciences Journal of Social Sciences Cilt: 20 Sayl: 36 / Volume: 20 Issue: 36 


\subsection{Turna}

Turna $^{17}$, İslam öncesi Türk kültürünün yanı sıra İslam dönemi Türk kültüründe de yer alan kuşlardan biridir. Temizkan (2014: 165166), bu kuş hususunda şu bilgiler aktarır: Gıyasettin Aytaş tarafından kaleme alınmış olan "Türkülerde Turna" başlıklı makaledir. Yazar, turnanın "Gök Tanrı'yı temsil ettiği için kutsallaştırıldığını" belirttikten sonra, söz konusu kuşun bu kutsallığını Alevî Bektaşî folklorunda da sürdürdüğünü ve Hz. Ali’yi temsil ettiğini söylemektedir... Özellikle halk hikâyelerinde turna, haber getiren, kendisinden haber sorulan, dertleşilen bir kuştur. Sıladan veya sevgiliden haber getirir.

"Turna", yeni yaşam alanlarını bulmak amacıyla göç eden bir kuş türüdür. $\mathrm{O}$, sürekli bir arayış içerisindedir ve yeni yerleri keşfetme çabası vardır. Feqiye Teyran'ın da sürekli “yeni şeyleri öğrenme çabası ve arzusu" içinde olan biri olmasıyla onun bu özellikleri turna kuşu ile özdeştirilir.

\subsection{Kumru}

Evli çiftlerin beraber mutlu bir şekilde vakit geçirme durumları kumru $^{18}$ kuşlarla bağdaştırılır. Ancak, geçmişte bu bölgede, evli çiftler bile olsalar, kadın erkeğin kol kola beraber gezmeleri pek rastlanır bir durum değildi. Muhittin Turan (2014: 33), "kumru" kuşu ile ilgili olarak şu hususlara yer verir: Kumru, Divan şiirinin kuş kadrosu içerisinde zarafeti, sevimliliği ve daha da önemlisi beğenilen sesiyle bülbülün ve her ikisi birden de yakıcı feryatlarıyla onları anımsatan âşığın akranıdır.

\footnotetext{
${ }^{17}$ Bk. Ek 17.

${ }^{18}$ Bk. Ek 18 .
}

Uludağ Üniversitesi Fen-Edebiyat Fakültesi Sosyal Bilimler Dergisi Uludağ University Faculty of Arts and Sciences Journal of Social Sciences Cilt: 20 Sayl: 36 / Volume: 20 Issue: 36 


\subsection{Bülbül}

Sesi güzel olan kimseler ile bülbül sesi arasında bir bağ kurulur. Bülbül ${ }^{19}$ bahar mevsimini ve dolayısıyla güzellikleri sembolize eder. Sinecen (2017: 125), bu hususta ve gül, bülbül ile diken ilişkisi konusunda şu hususlara yer verir: Bahar mevsimi de bütün haşmetiyle Allah'ın cemal suretinin tecelli ettiği zamandır... Gül, bülbül ve diken üçlüsü klasik şiirde sevgili, âşık ve rakibi simgeleyen en yaygın ögelerdir. Âşıklar için vuslat sevgiliyi görmektir ancak aşk için ayrılıkların da olması gerekmektedir. Ayrılık ise aşkın en yakıcı ve zor tarafıdır. Âşığın aşkta kemâlata ulaşması için aşkın sıkıntı ve dertlerine katlanması gerekmektedir. Dolayısıyla âşıkların aşk dertlerinden şikâyetleri usulendir, bir gerçeklik içermez. Onlar aşk derdinden memnunlardır, hoşnutlardır. Gülün yanındaki dikenler, acıtıcı, yakıcı olmaları yönüyle hiçbir zaman iyi karşılanmaz ancak gülün kıymetinin algılanması, onun hemen yakınındaki dikenlerdendir. Bu yönüyle gül ve diken hayatın bütününü de sembolize eder. Hayat hep gül olmadığı gibi hep diken de değildir. Güzel sesin birçok yerde bülbülün sesi ile bağdaştırıldığ 1 görülür. Güzel sese sahip olan Vanlı şair Feqiye Teyran'ın da bülbülle irtibatlandırıldığı görülür. Ayrıca bölgede sesi güzel olan birçok ses sanatçının da bülbülle özdeştirildiği görülür.

\subsection{Kuğu}

Keklik $^{20}$, bülbül, kumru ve turna gibi kuşlarda olduğu gibi "kuğu" da doğanın vazgeçilmez tasvirleri arasında yer alır. Adı geçen kuşlar gibi gizem ve tutkuyu temsil etmesinin yanında güzelliğin, gençliğin, kalp kazanmanın ve sevdanın sembolü olarak da gösterilir. Kış türü kuşlardan olan "kuğu" Van iline Sibirya'dan gelir ve Nisan ayında geriye göç eder. Yörede "beyaz kaz" olarak da bilinir. Ergin olan

\footnotetext{
${ }^{19}$ Bk. Ek 19.

${ }^{20}$ Bk. Ek 20.
}

Uludağ Üniversitesi Fen-Edebiyat Fakültesi Sosyal Bilimler Dergisi Uludağ University Faculty of Arts and Sciences Journal of Social Sciences Cilt: 20 Sayl: 36 / Volume: 20 Issue: 36 
kuğuların gagaları sarı renktedir. Böylece gagalarının rengine göre yaşları hakkında bilgi sahibi olabiliyoruz.

\subsection{Toy Kuşu}

Toy $^{21}$, farklı anlamları arasında "şenlik, şölen, ziyafet" anlamlarını taşımaktadır. Kazdan da daha büyük olan ve eti yenilebilen bu yabani kuş özellikleri itibarıyla bir tanesinin eti birçok kişiye yetebilecek miktarda olduğundan ve şenlik, şölen ve ziyafet gibi organizasyonlarda etinden istifade edebilecek olmasından bu ismi almış olması muhtemeldir.

\section{Feqiye Teyran}

Van'a bağlı Bahçesaray (Miks) ilçesinde dünyaya gelen ve kuşların diline aşina biri olarak bilinen Kürt Edebiyatı şairlerinden Feqiye Teyran kuş kültürü ile ilgili olarak Van İline ayrı bir zenginlik katmıştır. Fakire Teyran yazdığı şiir türüyle Türk Edebiyatı'nın şairlerinden Yunus Emre ile irtibatlandırılır. Şiirlerinde sade bir dil kullanır ve sıkça hayvanları, su gibi tabiat varlıklarını konuşturur. Asıl isminin Muhammed olduğu ve 1561-1644 yılları arasında yaşadığı ifade edilen bu şair ile ilgili olarak Sadini (2012: 171-173), şu hususları aktarır: Feqiye Teyran Mikslidir ve yine Miks'e bağlı Werezoz köyünde vefat etmiş̧ir, türbesi buradadır. Türbesi bu köyün arka tarafına düşmektedir. Ağaçlık bir yerdir. Burada bin yıllık ağaçlar mevcuttur. Mezarı belirgindir, hemen bitişiğinde başka bir mezar da var ama kime ait olduğu bilinmemektedir. Mezarında herhangi bir mezar taşı ya da işaret yoktur. Yine de Werezoz köylüleri ve civar köylerden gelenler burayı ziyaret ederler. Halk arasında kutsal kabul edilir. Buradaki ağaçlar ne kesilir ne de yakılır. Bunu yapanların musibete uğrayacağına inanılır. Bu ağaçların üzerinde kuşlara ait bir izin olmaması, buranın sakinleri tarafından kuşların Feqi'nin hatırı için burayı kirletmedikleri şeklinde yorumlanır

${ }^{21}$ Bk. Ek 21.

Uludağ Üniversitesi Fen-Edebiyat Fakültesi Sosyal Bilimler Dergisi Uludağ University Faculty of Arts and Sciences Journal of Social Sciences Cilt: 20 Sayl: 36 / Volume: 20 Issue: 36 
Bereh (2012: 195-196), şair Muhammed'in "Feqiye Teyran" ismiyle anılmasını ve kartal, bülbül, turna gibi kuşlara benzetilmesini şu şekilde açıklanır: Kartal (Teyr) kuşlar içinde en hızlı ve ilginç özelliklere sahip olan bir hayvandır. Onlar bütün kuşlardan daha yüksekte uçabiliyorlar. Av yetenekleri ve güçleri çok fazladır. Çok yükseklerden en küçük şeyleri de görür ve bir hayvanın hareketini hissedebilirler. Göz bebekleri kafalarına göre büyüktür ve $5 \mathrm{~km}$ 'ye kadar görebiliyorlar. Aile yaşantısında eşlerine ve yavrularına bağlıdırlar. Daha çok sürüngen hayvanlarla beslenirler. Doğadaki yaşam döngüsünde önemli ir role sahiptirler. Tabii ki bu özellikleriyle Feqi tarafindan sembol olarak kullanılması onun iyi bir unvan olduğuna işarettir. O Feqi'ye Teyran'dır. Çünkü kartallar aile hayatında ahlak sahibidirler. İyi işçidirler. Diğer kötü hayvanların tersine bir özelliğe sahiptirler. Hayata üstten bakarlar. Her şeyi kolayca görürler. Feqi de, toplumdan önce olan entelektüellerin öğrenicisi olduğunu söylemek istiyor. İyilik için yaşayan, kötülüğe karşı olan ve iyi bir ahlaka sahip olan aydınlar...

Bülbül kuşların içinde en güzel sesli olanı ve aşk için şakıyanıdır. O güle âşıktır. Gül de, Allah'tır, insandır, toplumdur ve tabiattır. Feqi de sürekli tatlı, akıcı, orijinal ve güzel sesiyle söylüyor ve terennüm ediyor. Kimin için? Allah için, insan için, her güzel şey için söylüyor.

Feqi göçebe bir hayat yaşadığı için (Cizre'den Van'a kadar) kendini turnaya benzetmiştir. Feqi sürekli bir arayış ve tarayış içerisinde olduğunu söylemek istiyor bize. "Daha onurlu bir hayat ve Rabbime ulaşmak için sürekli ibadet etmeliyim ve alnımda iz çıkana kadar başımı secdeden kaldırmamalıyım" diyor. Aynı zamanda o bir derviştir. İyilik, tabiatın koruyucusu, toplumu ileriye taşıyan ve yeni bir yaşamın kurucusu olan bir derviştir. 


\section{Değerlendirme ve Sonuç}

İnsan çevresinde gördüğ canlı ve cansız birçok varlıktan bir şekilde etkilendiği gibi bazen de hiç görmediği bazı varlıkları hayalinde canlandırır. Nihayetinde, ister hayali ve ister gerçek varlık olsun her biri insanın kafasını bir şekilde meşgul eder ve ona bir anlam biçmeye çalışır. Bunun neticesinde de paylaşılan düşünceler bir toplumun kültürünün bir kısmını oluşturur. Bu anlamda, kuşlarla ilgili konuyu irdelediğimizde de gerçekte var olan kuşların yanı sıra hayali (mitolojik) birçok kuş türünün kültür ve sanatımızda yer aldığg görülür. Bilhassa anka ve hüma gibi kuşlarının etkisi yaygın olarak görülür.

Çevremizde gördüğümüz kuşlar görünümleriyle, hareketleriyle, çıkardıkları sesleriyle (ötüşleriyle) vb. diğer özellikleriyle insanlar üzerinde bir etki bırakırlar ve bu etkiye göre insanların her bir kuş türüne bir anlam çıkardığı, netice itibarıyla da kendi karakter ve davranışlarıyla da bir bağ kurmaya çalıştığı görülür. Bu anlamda, kuşlar çeşidine göre güzelliğin, iyiliğin, mutluluğun, şefkatin, sadakatin, dürüstlügün, nezaketin, özgürlüğün, ön görülüğün, hürmet göstermenin, iyi bir aile bireyi olmanın, zorluklara karş1 direnişin gibi birçok olumlu niteliğin yanı sıra kibir, gurur, gösteriş, hile, aldatma, kötülük vb. kavramların sembolü olmuşlardır.

İnsan, olumlu ve olumsuz davranışlara sahip olabiliyor. Küçük menfaatleri için etrafındaki insanlara ve diğer varlıklara zarar verebiliyor. Ancak kültür ve inancımızın bizler için en büyük kalkan olduğunu görmekteyiz. Kuşlara karşı acımasız olmamamız için yine kuşlar konuşturulmak suretiyle insanların bu konuda uyarıldığ 1 görülür. "Bir lokma et için beni öldürmekle eline ne geçer" gibi sözler buna güzel bir örnektir. Diğer taraftan insanların kendisine iyilik yapan her varlığa karşı vefalı olduğu da görülür. Geçmişte insanlığa faydası olmuş "güvercin" ve "hüthüt" gibi kuşlara karşı sayg1 besler, onlara zarar vermez. 
Zengin bir kuş potansiyeline sahip olan Van ve Hakkâri yöresinde kuşların kültürel yansımalarının yanı sıra sanat eserlerine de önemli yansımaları görülür. Akdamar Kilisesi ve Yedikilise Manastırı üzerinde bölgede bulunan birçok kuş türünün yanı sıra bu bölgede bulunmayıp ancak Hristiyanlık tarafindan kutsal sayılan kabartma kuş figürüne rastlanır. Yörede çok önemli bir yere sahip olan dokuma ve örgü işleri üzerinde de kuş figürlerine sıkça yer verilir. Dokumada görülen hayvan figürlerinde İran sanatının etkisinin yanı sıra yörede farklı motiflerin birer haberleşme vasıtası olarak kullanmasının etkisine de bağlanabilir. Kuşların diline aşina olarak bilinen şair Feqi'ye Teyran'ın da bu bölgede edebiyatın yanı sıra kuşlarla bağlantılı kültür ve sanat üzerinde de önemli bir etkiye sahip olduğu söylenebilir.

Sonuç; kuşların sadece sanatımızın değil yaşamımızın her alanında bizi etkiledikleri görülür. Doğanın önemli bir unsuru ve vazgeçilmezi olan bu yaratıkların hayal dünyamıza, yaşantımıza, kültürümüze ve sanatımıza kattığı anlam ve güzellikleri sıralamak mümkün değil. $\mathrm{Bu}$ anlamda, kuşların Van-Hakkâri sanat eserlerine olduğu gibi kültürüne de önemli yansımalarının olduğu görülür.

\section{Kaynaklar}

Alp, K. Özlem (2009). Orta Asya'dan Anadolu'ya Kültürel Sembollere Giriş. Ankara: Eflatun Yayınevi.

Bereh, Berken (2012). "Ey Su ve Su". Feqiye Teyran - Muhabbet Yolu, Van Valiliği, s. 195-196.

Bilic, Tomislav (2016). "The Swan Chariot of a Solar Deity". Greek Narratives and Prehistoric Iconographys, Documenta Praehistorica, s. 43, s. 445-466.

Collins, Arhur H. (1913). Symbolism of Animals and Birds: Represented in English Church Architecture, New York: McBride, Nast \& Company.

Uludağ Üniversitesi Fen-Edebiyat Fakültesi Sosyal Bilimler Dergisi Uludağ University Faculty of Arts and Sciences Journal of Social Sciences Cilt: 20 Sayı: 36 /Volume: 20 Issue: 36 
Çoruhlu, Yaşar (1988). Anadolu Selçuklularının Taş Tezyinatına Orta Asya Ile Bağlantıları. Yüksek Lisans Tezi. İstanbul: Mimar Sinan Üniversitesi.

Daşdağ, F. Evren (2017). “Görsel İletişimin Tarihi, Kültürel ve Estetik Nesnesi Olan Diyarbakır Surları ve Sembolik Motifleri”. Mühendislik Dergisi, C. 8, S. 2, s. 307-318.

Durmuş, Atilla ve Özdemir Adızel (2013). "Van İlinin Ornito-Turizm (Kuş Turizmi) Potansiyeline Sahip Sulak Alanları". Van Turizmi Geleceğini Arıyor, Çalıştay Kitabı, s. 194.

Eskigün, Kübra (2006). Klasik Türk Şiirinde Efsanevi Kuşlar. Yüksek Lisans Tezi. Kahramanmaraş: Sütçü İmam Üniversitesi.

Karaca, Yalçın (2017). "Van Yedikilise Manastırı Mimari Plastik Süslemelerdeki Kuş Figürleri”. XX. Uluslararası Ortaçă̆ Türk Dönemi Kazlları ve Sanat Tarihi Araştırmaları Sempozyumu, C. 2, Sakarya Üniversitesi Yayınlart, s. 964-984.

Oral, M. Zeki (1954). Hazret-i Mevlana Dergâhindaki Şaheserlerden Nisantası. Ankara: Türk Tarih Kurumu Basımevi.

Ögel, Bahaeddin (2003). Türk Mitolojis-1. Ankara: Türk Tarih Kurumu Basımevi.

Özel, Nilüfer (2018). "Grafik Bir Sembol Olarak Anadolu Selçuklularında Çift Başlı Kartal". The Turkish Online Journal of Design, Art and Communication - TOJDAC, C. 8 S. 3, s. 551-559.

Parla, Canan (2015). “Diyarbakır Dă̆ Kapısı'nın Figürlü Kabartmaları". Asos Journal, Akademik Sosyal Araştırmalar Dergisi, S. 12, s. 1-18.

Sadini, M.X. (2012). "Feqiye Teyran'1n Yurdu". Feqiye Teyran Muhabbet Yolu", Van Valiliği, s.171-173.

Uludağ Üniversitesi Fen-Edebiyat Fakültesi Sosyal Bilimler Dergisi Uludağ University Faculty of Arts and Sciences Journal of Social Sciences Cilt: 20 Sayı: 36 / Volume: 20 Issue: 36 
Sever, Mustafa (1999). "Türk Mitolojisinde Kuşlar". Millî Folklor, s. 42, s. 83-88.

Sinecen, Fatma (2017). "Usûlî Divanı'nda Kuşların Sembolik Değerleri". Journal of Turkish Language and Literature, C. 3, S. 3, s. 125-128.

Temizkan, Mehmet (2014). "Türk Kültüründe ve Alevi-Bektaşi İnancında Turna”. Millî Folklor, S. 101, s. 165-166.

Turan, Muhittin (2014). “Ahmedi Divanı'nda Kuşlar”, Asos Journal, Akademik Sosyal Araştırmalar Dergisi, S. 7, s. 23-37.

\section{Kaynak kişiler}

Anber Buğrul ( 88), Çavuşlu Köyü, Hakkâri.

İsmail Güler (75), Çavuşlu Köyü, Hakkâri

Selim Bulut (70), Yüksekova. 


\section{Ekler}

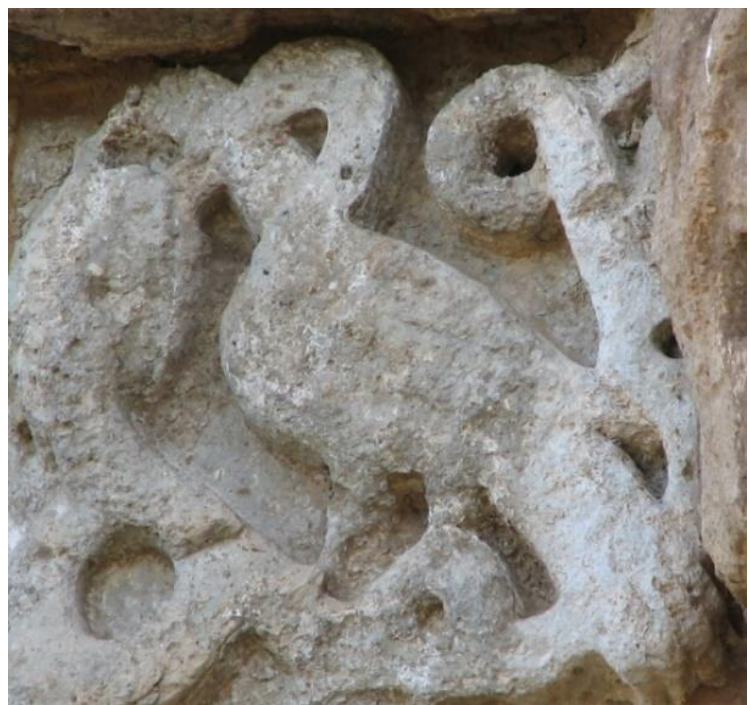

Ek 1. Özdemir Adızel, 2006, Akdamar Kilisesi, Kabartma "kuğu” figürü

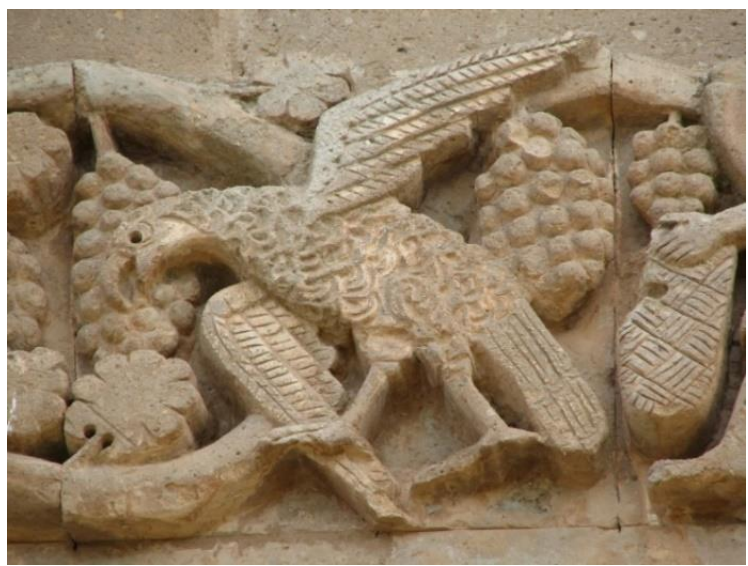

Ek 2. Özdemir Adızel, 2006, Akdamar Kilisesi, üzüm gagalayan bir kartalın kabartma figürü

Uludağ Üniversitesi Fen-Edebiyat Fakültesi Sosyal Bilimler Dergisi Uludağ University Faculty of Arts and Sciences Journal of Social Sciences Cilt: 20 Sayl: 36 / Volume: 20 Issue: 36 500 


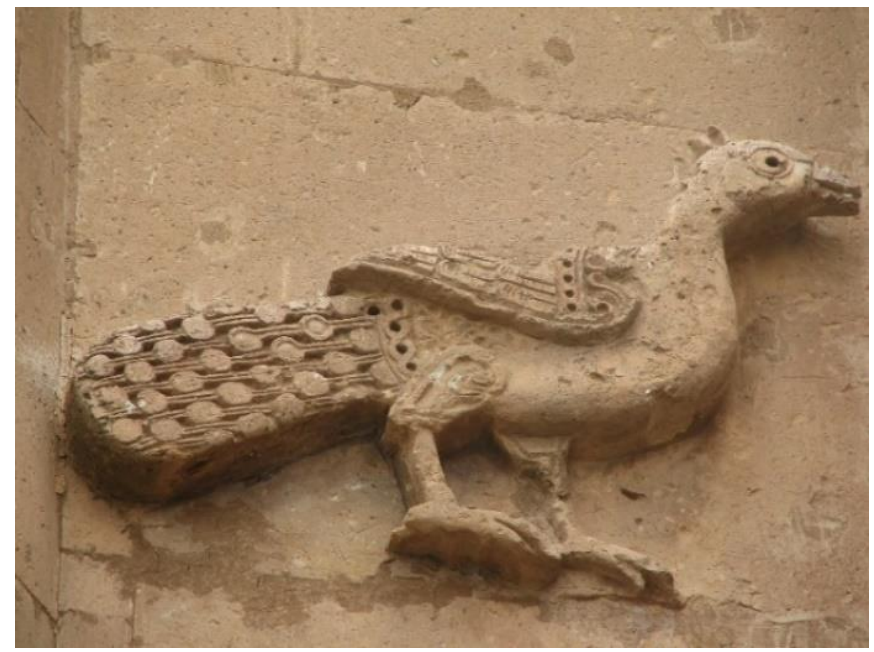

Ek 3. Özdemir Adızel, 2006, Akdamar Kilisesi, Kabartma "tavus kuşu” figürü

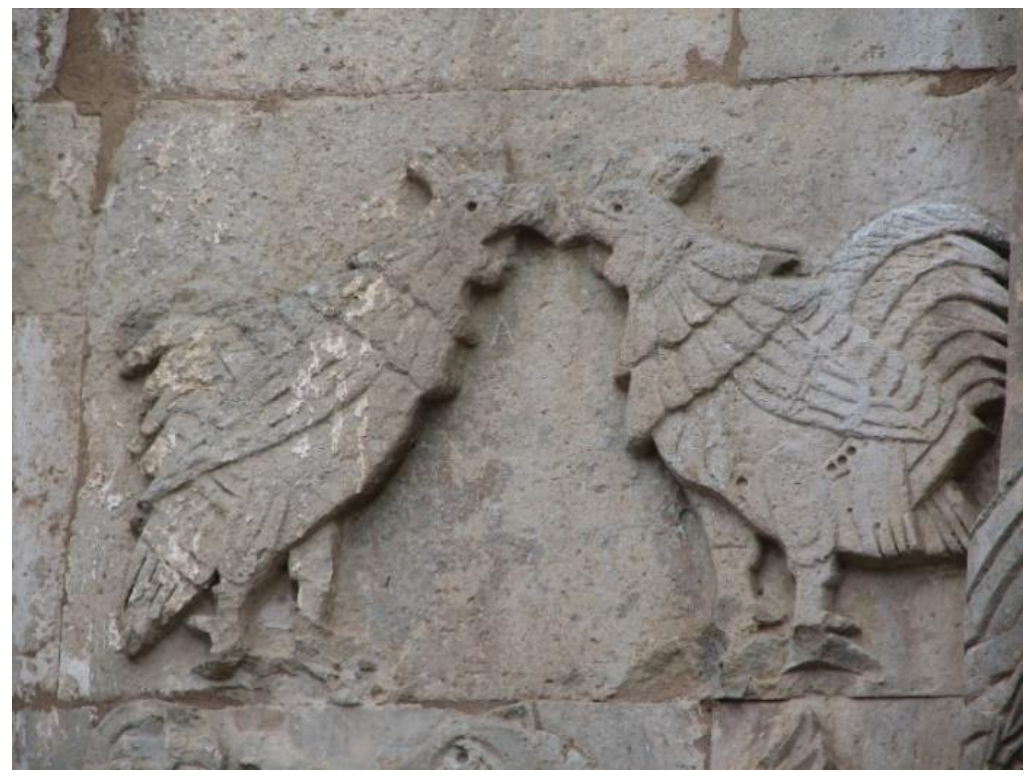

Ek 4. Özdemir Adızel, 2006, Akdamar Kilisesi, Horoz döğüşü figürü

Uludağ Üniversitesi Fen-Edebiyat Fakültesi Sosyal Bilimler Dergisi Uludağ University Faculty of Arts and Sciences Journal of Social Sciences Cilt: 20 Sayl: 36 / Volume: 20 Issue: 36 


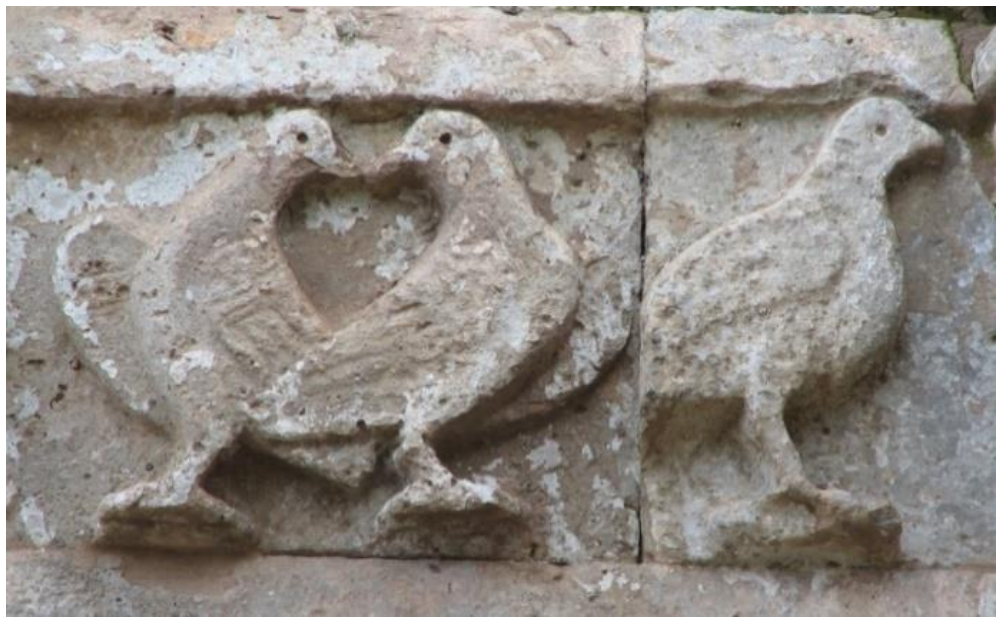

Ek 5. Özdemir Adızel, 2006, Akdamar Kilisesi, üç güvercine ait kabartma figür

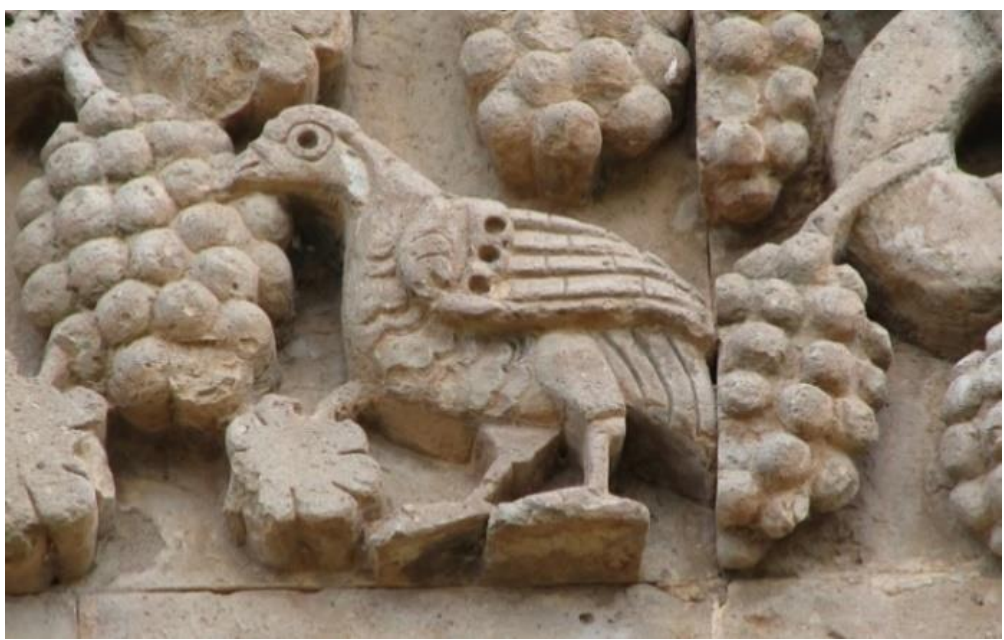

Ek 6. Özdemir Adızel, 2006, Akdamar Kilisesi, Üzüm gagalar vaziyette betimlenen keklik figürü

Uludağ Üniversitesi Fen-Edebiyat Fakültesi Sosyal Bilimler Dergisi Uludağ University Faculty of Arts and Sciences Journal of Social Sciences Cilt: 20 Sayı: 36 / Volume: 20 Issue: 36 


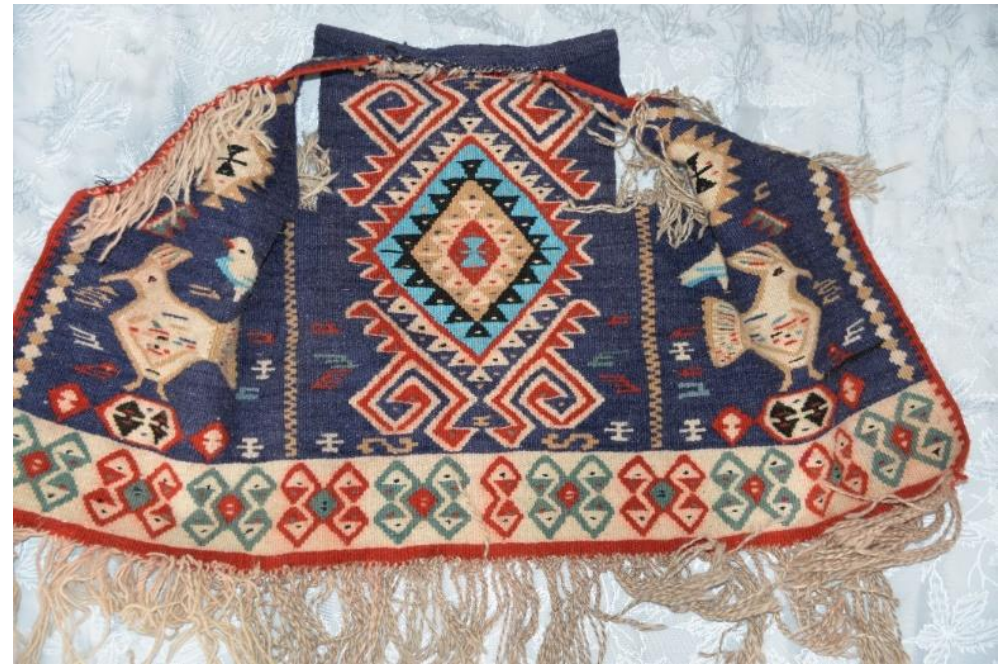

Ek 7. Hasan Buğrul, 2018, Hakkâri'nin Çukurca ilçe merkezinde dokumasına rastlanan hüthüt kuşu \& "lüleper / muhabbet kuşu", koçboynuzu, bukağı vb. motiflere sahip kadın kilim yeleği.

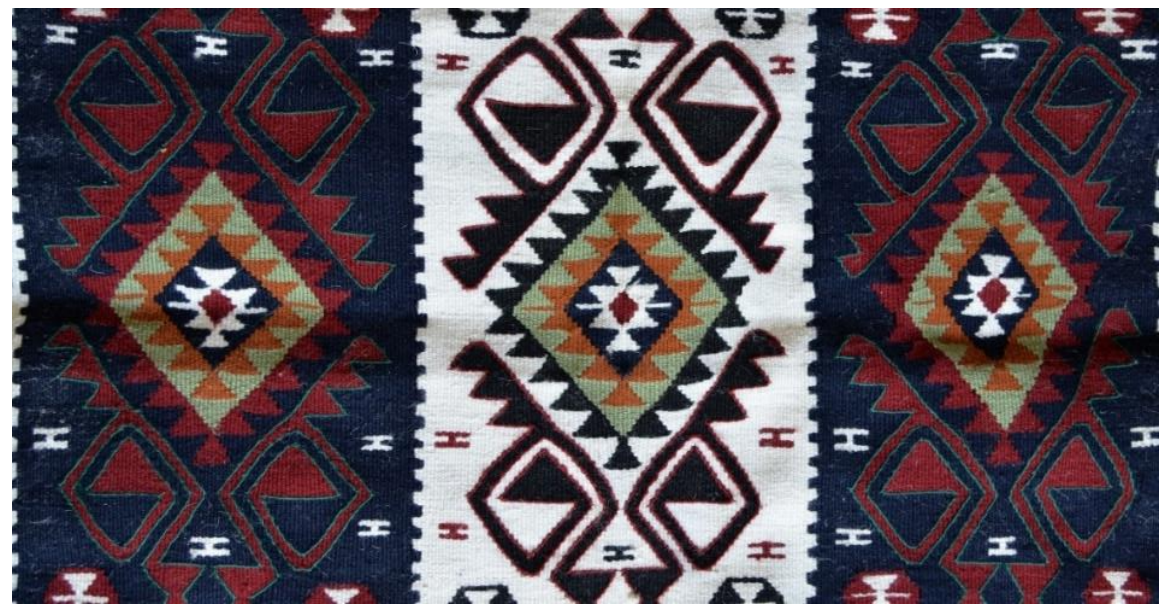

Ek 8. Hasan Buğrul, 2018, Üç kuşak şeklinde dokuması yapılan muhabbet kuşu motifli kilim. Geçitli - Hakkâri. Yörede bu motif "lüleper" olarak bilinmektedir.

Uludağ Üniversitesi Fen-Edebiyat Fakültesi Sosyal Bilimler Dergisi Uludağ University Faculty of Arts and Sciences Journal of Social Sciences Cilt: 20 Sayl: 36 / Volume: 20 Issue: 36 


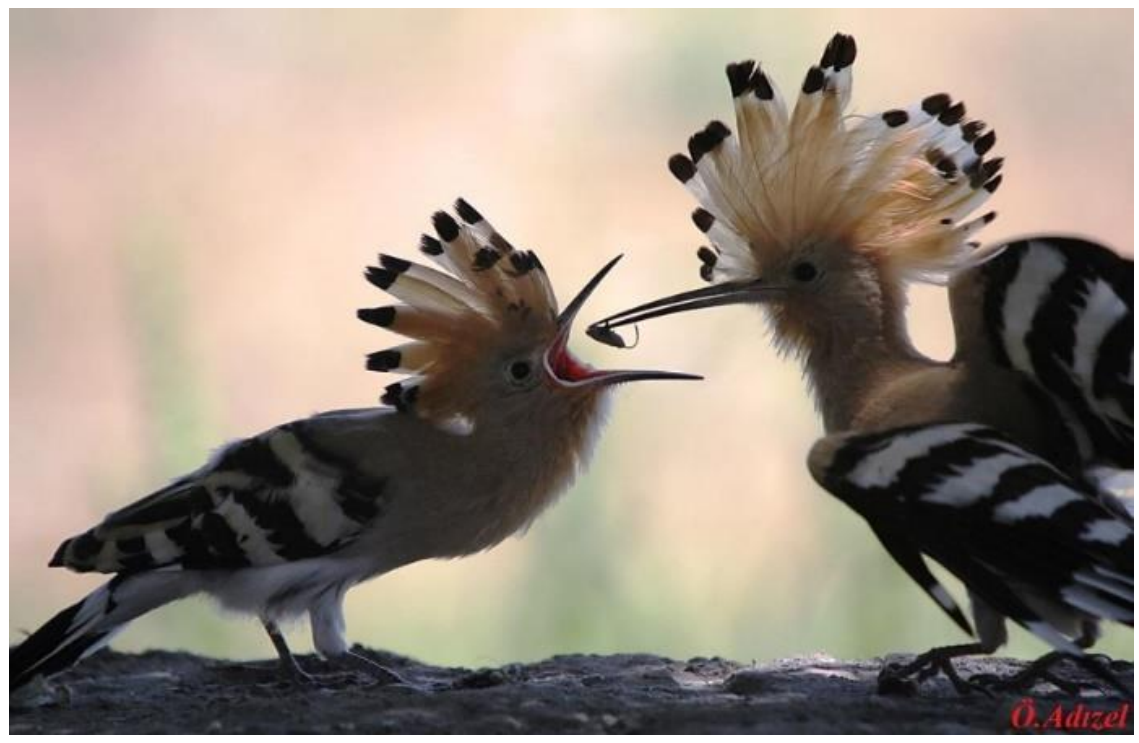

Ek 9. Özdemir Adızel, Yavrusunu besleyen bir hüthüt kuşu.

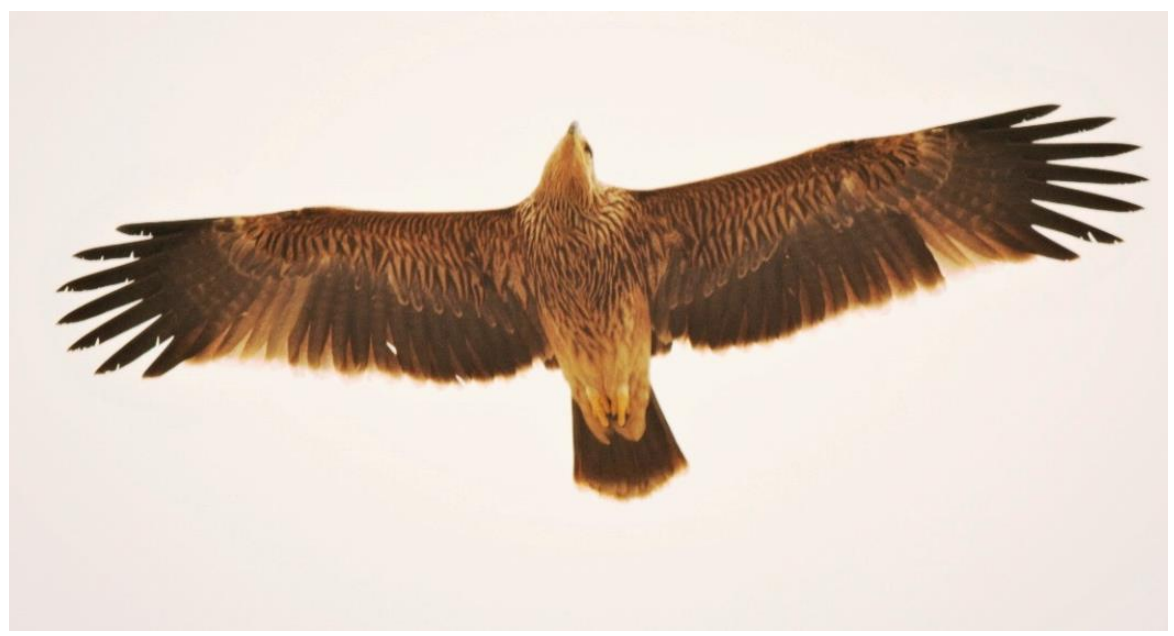

Ek 10. Erkan Azizoğlu. Şah kartalı

Uludağ Üniversitesi Fen-Edebiyat Fakültesi Sosyal Bilimler Dergisi Uludağ University Faculty of Arts and Sciences Journal of Social Sciences Cilt: 20 Sayı: 36 / Volume: 20 Issue: 36 


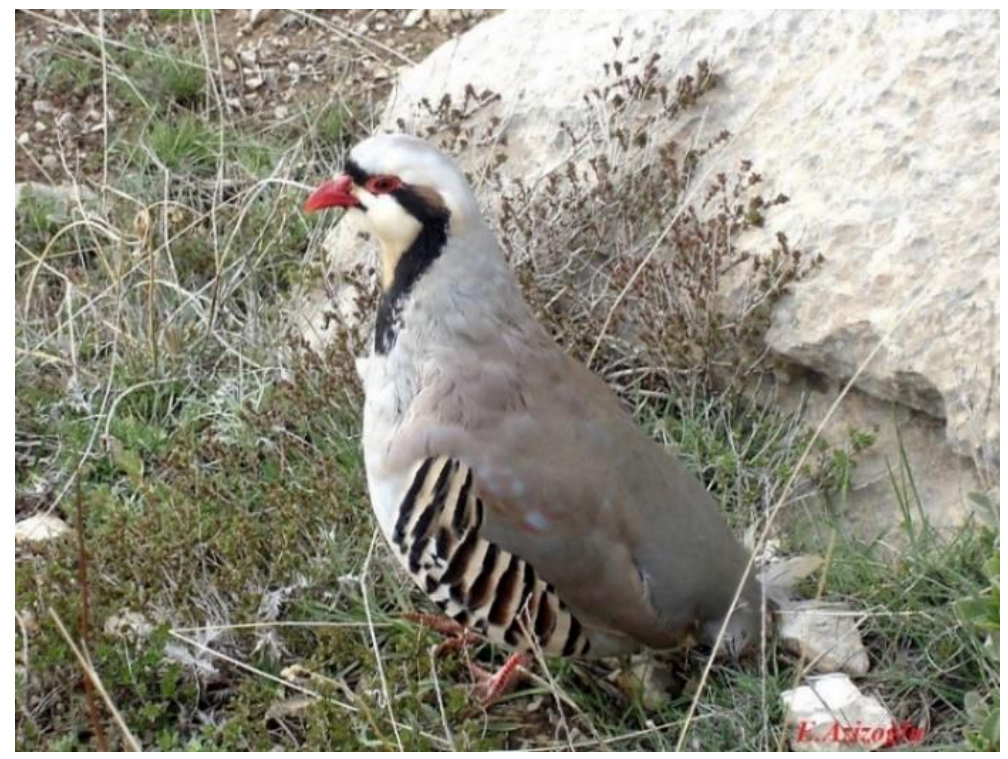

Ek 11. Erkan Azizoğlu. Keklik

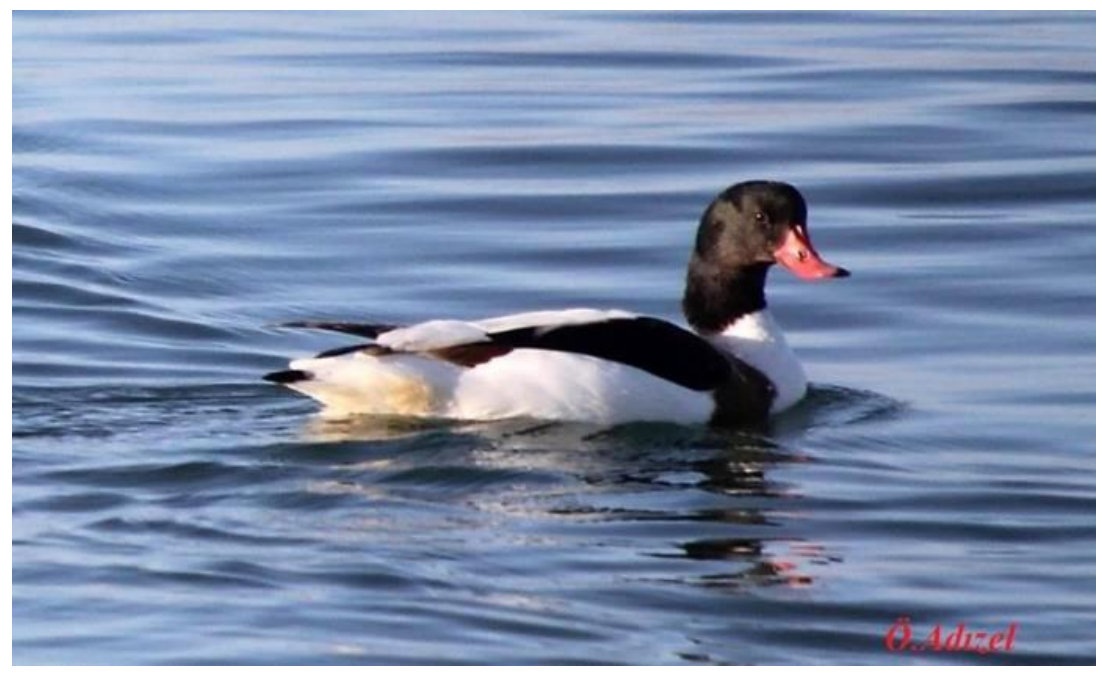

Ek 12. Özdemir Adızel, Dişi bir Suna kuşu.

Uludağ Üniversitesi Fen-Edebiyat Fakültesi Sosyal Bilimler Dergisi Uludağ University Faculty of Arts and Sciences Journal of Social Sciences Cilt: 20 Sayl: 36 / Volume: 20 Issue: 36 


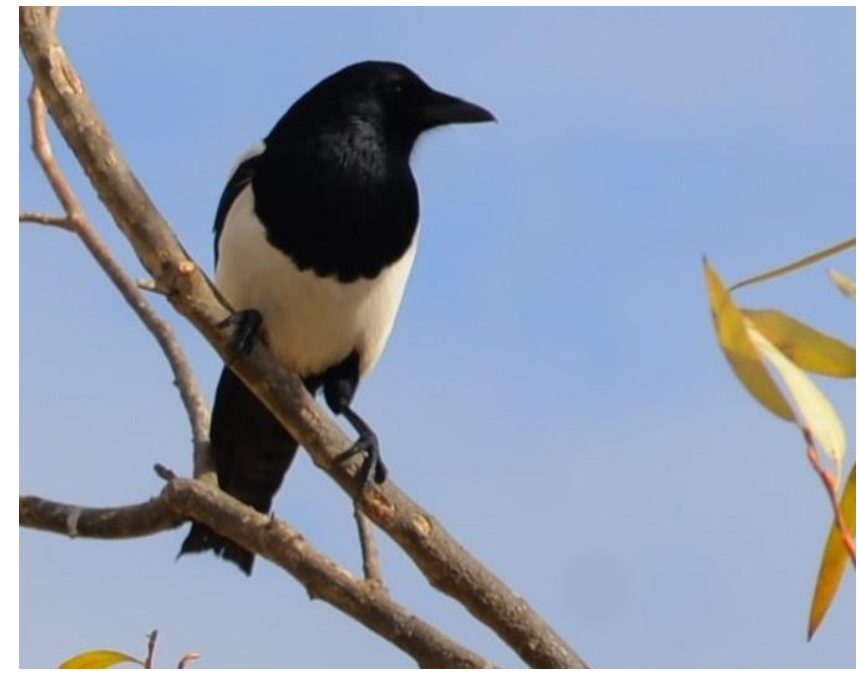

Ek 13. Hasan Buğrul. Alacalı karga

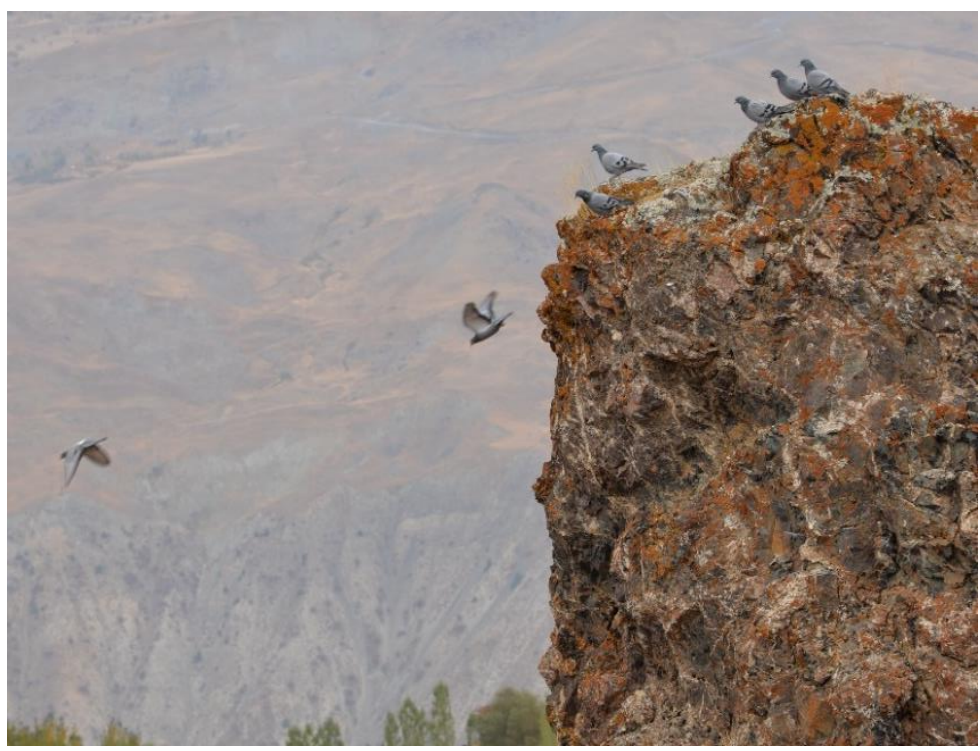

Ek 14. Hasan Buğrul, Kaya Güvercini

Uludağ Üniversitesi Fen-Edebiyat Fakültesi Sosyal Bilimler Dergisi Uludağ University Faculty of Arts and Sciences Journal of Social Sciences Cilt: 20 Sayl: 36 / Volume: 20 Issue: 36 506 


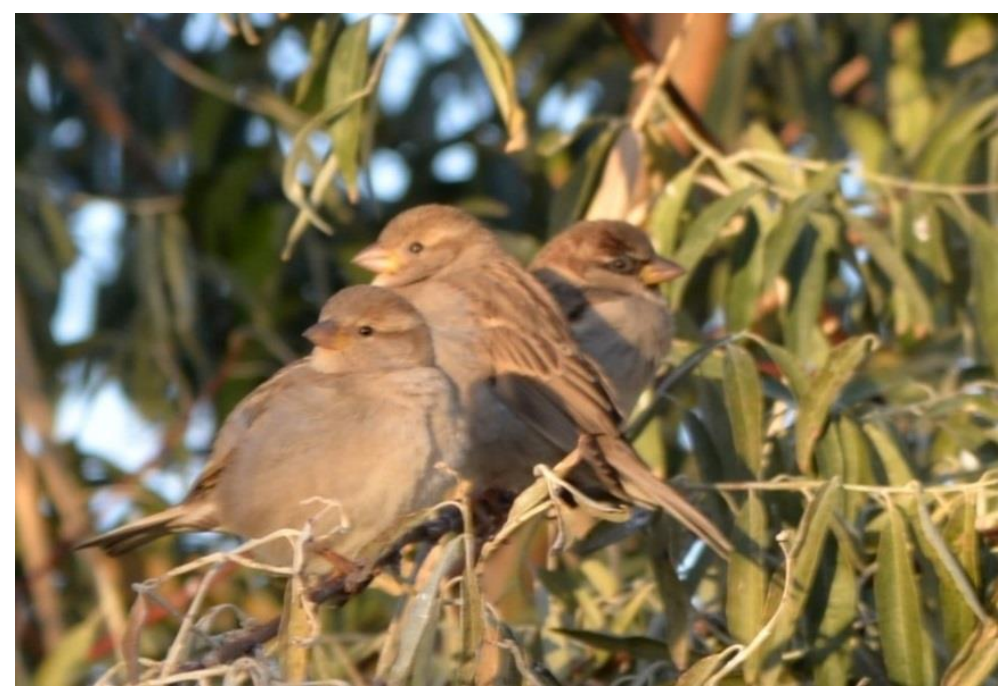

Ek 15. Hasan Buğrul, Serçe kuşu

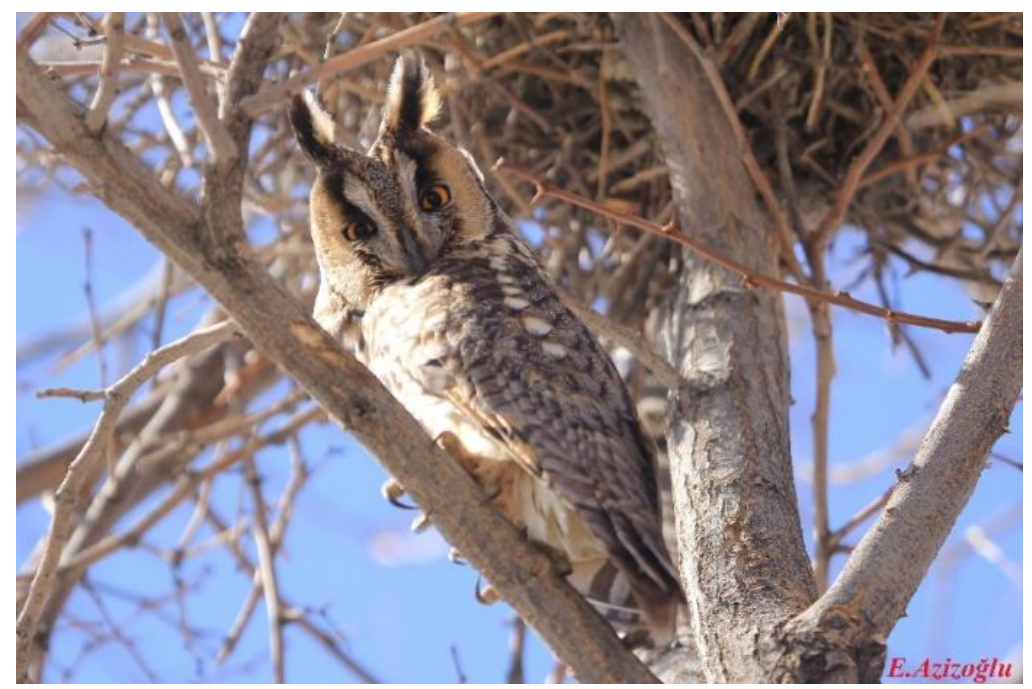

Ek 16. Erkan Azizoğlu, Kulaklı orman baykuşu

Uludağ Üniversitesi Fen-Edebiyat Fakültesi Sosyal Bilimler Dergisi Uludağ University Faculty of Arts and Sciences Journal of Social Sciences Cilt: 20 Sayl: 36 / Volume: 20 Issue: 36 


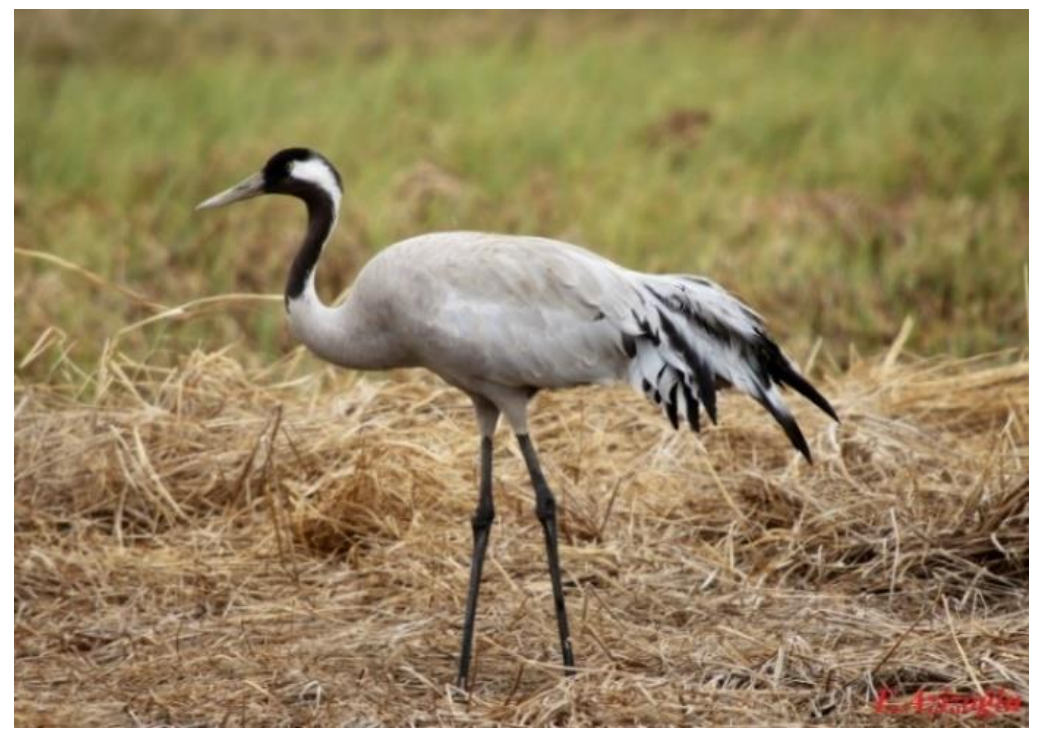

Ek 17. Erkan Azizoğlu, Turna.

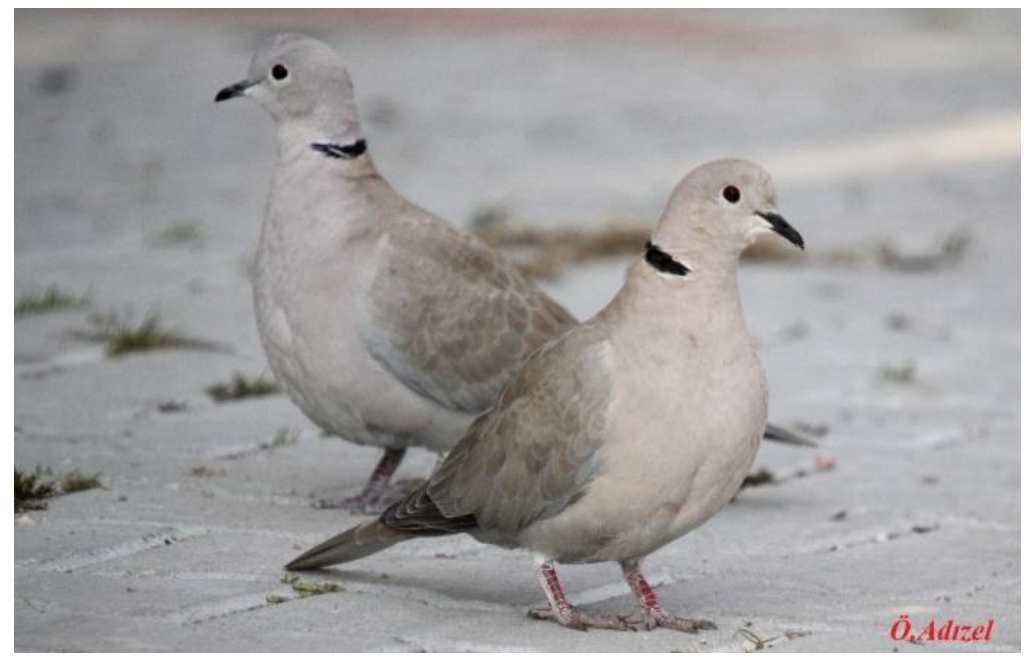

Ek 18. Özdemir Adızel, Kumru

Uludağ Üniversitesi Fen-Edebiyat Fakültesi Sosyal Bilimler Dergisi Uludağ University Faculty of Arts and Sciences Journal of Social Sciences Cilt: 20 Sayl: 36 / Volume: 20 Issue: 36 508 


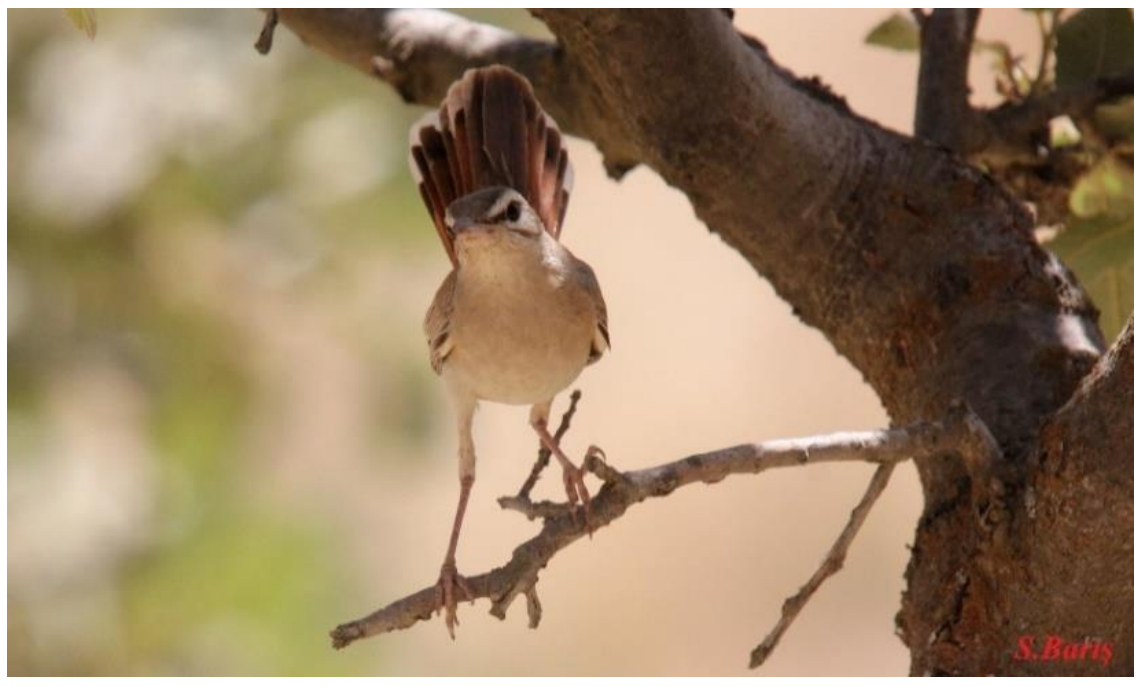

Ek 19. Süleyman Barış, Bülbül.

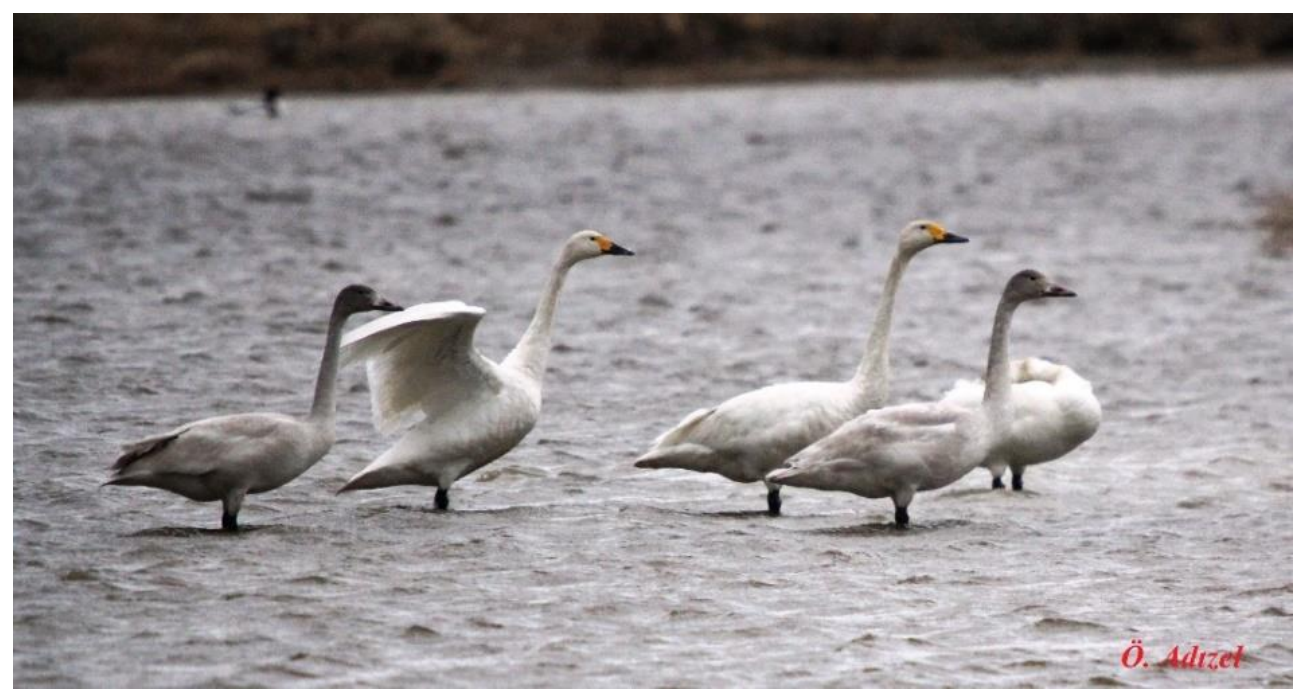

Ek 20. Özdemir Adızel, Kuğu kuşu.

Uludağ Üniversitesi Fen-Edebiyat Fakültesi Sosyal Bilimler Dergisi Uludağ University Faculty of Arts and Sciences Journal of Social Sciences Cilt: 20 Sayl: 36 / Volume: 20 Issue: 36 


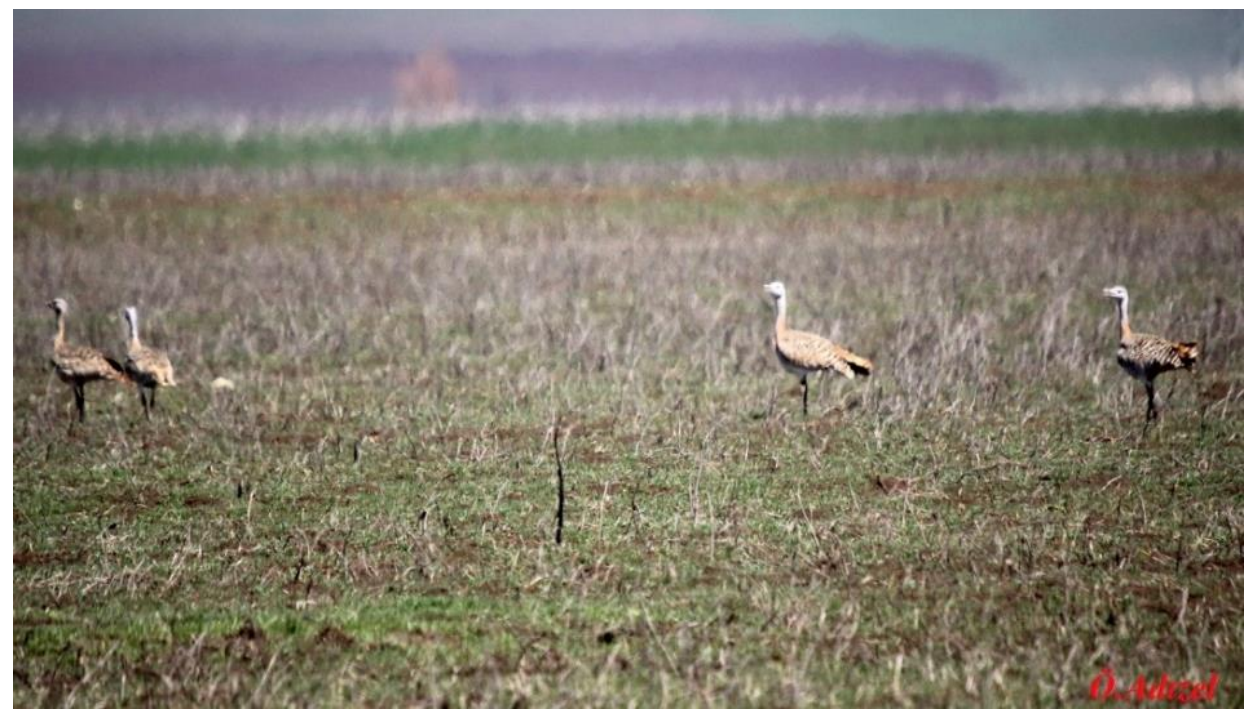

Ek 21. Özdemir Adızel, Toy kuşu.

Uludağ Üniversitesi Fen-Edebiyat Fakültesi Sosyal Bilimler Dergisi Uludağ University Faculty of Arts and Sciences Journal of Social Sciences Cilt: 20 Sayl: 36 / Volume: 20 Issue: 36 


\section{EXTENDED ABSTRACT}

Due to being in the routes of bird migration and having a lot of wetlands, it is seen that Van-Hakkâri provinces are very rich in terms of bird population. In the Van Lake basin, there are about 230 spices of the birds. In addition to being one of the most important items of nature, birds are indispensable elements in the culture, beliefs and arts of the societies. Considering the art and culture of Van and Hakkâri, we can say that birds also appear to have a great place in them. In the literature and field work made, admirable bird figures were found on the historical monuments in Van and on the weaving assets of Hakkâri region. In order to be able to detect the cultural reflection of the birds in this region, we tried to obtain information by questionanswer method.

Considering the beliefs and cultural implications of birds, hoopoe, rock dove and stork are among the birds seen as sacred. Hunting of the other birds is not approved in the region. The response to the hunting of birds is also expressed by means of having the birds talk. On the other hand a woman whose physical appearance is beautiful is associated with chukar and a woman who is clean and wellgroomed is linked to drake. When examining how birds have been reflected in the works of art; as historical monuments, Akdamar Church and Yedikilise Monastery attract great attention from this aspect. Besides giving a place to the figures of the birds such as grackle, dove / rock dove, stork, swan, crow, nightingale and goose, totally 26 figures, on the walls of the Yedikilise Monastery, and swan, shelduck / sheldrake, small birds of prey, eagles, sparrow hawk, guinea fowl, cock (cock fighting), partridge, quail, bustard, seagull, dove, turtledove and crow on the façade of Akdamar Church which are found in the region, we see bird species such as "peacock" which is not encountered in the region, but regarded as sacred. One of the most interesting figures is the one which reflects a happy dove family, a pair of doves with two eggs, but under threat due to a snake. Of course, there are some more figures each of which reflects a different story or an event in terms of culture or religion.

In addition to historical works, stylized bird figures are also frequently found in weaving and knitting works. The figures on these elements usually express feelings such as happiness, joy, love and so on that cannot be conveyed in verbal and written words to the other side. In addition to these, Feqiye Teyran, born in Misk (Bahçesaray), Van, is defined as a dervish and poet familiar to the language of birds. Feqi, is linked with an "Eagle" as he was farseeing, linked with a "Crane" as he was in search of a new life and a constant search and linked with a "Nightingale" as he had sweet, fluent, original and beautiful voice.

Uludağ Üniversitesi Fen-Edebiyat Fakültesi Sosyal Bilimler Dergisi Uludağ University Faculty of Arts and Sciences Journal of Social Sciences Cilt: 20 Sayı: 36 / Volume: 20 Issue: 36 
In the research conducted, we saw that very extensive works have been done about the birds in the field of biology and veterinary by the lecturers from our university (Van Yüzüncü Yll Univeristy). However, a detailed study related to the reflection of birds to culture and art of Van-Hakkâri region was not found. By means of this academic study, it is aimed to contribute to the culture, art and tourism of the region in this field. 